\title{
Magnetic Nanocomposite Derived from Nopal Cactus Biopolymer and Magnetic Nanoparticles Used for the Microalgae Flocculation of Aqueous Solution
}

Lan Huong Nguyen, ${ }^{\mathrm{a}}$ Huu Tap Van, ${ }^{\mathrm{b}, *}$ Duong Hong Quan, ${ }^{\mathrm{c}}$ and Phuong Thuy Thi Pham ${ }^{\mathrm{d}}$

\begin{abstract}
A magnetic nanocomposite, using a Nopal cactus-derived biopolymer in combination with $\mathrm{NH}_{4} \mathrm{OH}$-modified cobalt superparamagnetic $\left(\mathrm{CoFe}_{2} \mathrm{O}_{4}\right.$ ) nanoparticles, was developed as a green flocculant system for recovery of microalgae from aqueous solutions. The obtained magnetic nanomaterials were subsequently dispersed in the biopolymer matrix with the support of ultrasonic waves. The effects of various factors on pectin extraction, fabrication of nanocomposites, and the flocculation process of microalgae were also studied. The characteristics of the obtained materials (pectin, modified magnetic nanoparticles, and nanocomposites) were evaluated via X-ray powder diffraction, scanning electron microscopy, transmission electron microscopy, vibrating sample magnetometry, thermogravimetricdifferential scanning calorimetry, Fourier transform infrared spectroscopy, and zeta potential analysis. The optimal conditions for pectin extraction from Nopal cactus, as well as the fabrication of magnetic nanoparticles, modified magnetic nanoparticles, and nanocomposite were reported. The characteristic data of the fabricated materials showed heat resistance and abundant surface functional groups with high magnetization. The observed flocculation was attributed to the aggregation of unstable and small particles through surface charge neutralization, electrostatic patching, and/or bridging after addition of flocculants. The results showed that the nanocomposites could be a potential green flocculant for recovering microalgae with low cost and high efficiency.
\end{abstract}

Keywords: Flocculation; Magnetic; Microalgae; Nanocomposite; Nopal cactus

Contact information: a: Faculty of Environment-Natural Resources and Climate Change, Ho Chi Minh City University of Food Industry (HUFI), Ho Chi Minh City 70580 Vietnam; b: Faculty of Natural Resources and Environment, TNU - University of Sciences (TNUS), Tan Thinh Ward, Thai Nguyen City 250000 Vietnam; c: Ho Chi Minh City University of Food Industry (HUFI), Ho Chi Minh City 70580 Vietnam; d: Faculty of Biological Technology, Ho Chi Minh City University of Food Industry (HUFI), Ho Chi Minh City 70580 Vietnam;

* Corresponding authors: Huи Tap Van (tapvh@tnus.edu.vn)

\section{INTRODUCTION}

In recent years, rapid industrialization and population growth in developing countries has continuously put pressure on the quality of the living environments, especially in terms of water resources. More and more rivers have become polluted due to the effluents produced by manufacturing factories. Water pollutants have appeared as threats to entire environments as well as human health; hence it is essential to remove them from the water. Specifically, the water contamination by various nutrients, e.g., nitrogen and phosphorus discharged from domestic, agriculture and industrial wastewater (piggery effluent, food processing factories, leachate, etc.), are the primary causes of the 
eutrophication of the water bodies due to stimulating growth of microalgae, which leads to formation of "algal blooms" (McNeary and Erickson 2013). The rapid growth of microalgae causes serious concerns for human and aquatic animals since the depletion of dissolved oxygen causes the death of aquatic animals (McNeary and Erickson 2013). Despite these serious environmental problems, microalgae are considered a potential alternative feedstock for biofuel production (Milledge and Heaven 2013; Matter et al. 2019). Thus, efficiently harvesting microalgae from water is not only important for the remediation of eutrophicated water bodies, but also for biofuel production.

So far, a large number of technologies have been used to recover microalgae from water bodies. Popular methods include flocculation, centrifugation, filtration, flotation, sedimentation, and electrophoresis (Renault et al. 2009; Milledge and Heaven 2013 Branyikova et al. 2018). Each method possesses its own advantages and disadvantages. Among them, coagulation/flocculation is one of the most popularly used methods to recover microalgae from water, due to its simplicity and economic feasibility (Branyikova et al. 2018). Traditionally, the popular coagulants used in wastewater treatment are comprised of poly aluminium chloride (PAC), aluminium sulphate, ferric sulphate, ferric chloride, ferrous sulphate, lime, and polymers (Renault et al. 2009).

Despite their outstanding effectiveness, the chemical residues left after the treatment might degrade the quality of the water and cause potential health risks in humans, in addition to raising the cost of treatment. Specifically, addition of commonly used flocculant systems causes an increase in residual metal concentrations in water, and there can be a huge amount of waste sludge containing acrylamide oligomers (Renault et al. 2009; Teh et al. 2016). Moreover, it was found that the excess amount of aluminium in water after coagulation-flocculation treatment using aluminium sulphate as the coagulating agent is one of the causes of Alzheimer's disease (Renault et al. 2009). In addition, conventional flocculants can cause changes in culture medium, i.e., changes in $\mathrm{pH}$, nutrients, temperature, and dissolved oxygen. The conventional flocculants supplemented in culture medium can trigger changes in the composition of microalgae cells (Ho et al. 2009). Therefore, there has been a downward trend in the usage of conventional chemicals, e.g., aluminium sulphate and ferric sulphate, for recovery of microalgae due to their high cost, dosage, and biomass contamination by their residue (Ho et al. 2009, 2010). Thus, it is necessary to seek an environmentally friendly flocculant from living organisms as the alternative, in order to decrease the effects of chemical contamination (Ho et al. 2009; Granados et al. 2012).

Biopolymers derived from natural materials are known as low cost, non-toxic, and ecology-friendly materials (Ho et al. 2009; Renault et al. 2009; Matter et al. 2019). Recently, many biopolymers have been developed using chitin or chitosan and starch (Renault et al. 2009; Chen et al. 2014; Rampino et al. 2016) or pectin (Ho et al. 2009, 2010). Pectin is derived from various waste materials, e.g., extracted from citrus peels (Joye and Luzio 2000), Nopal (Cárdenas et al. 2008), and Opuntia spp. (Goycoolea and Cárdenas 2003), whereas chitin or chitosan is found in shells of crustaceans such as shrimp, crabs, and lobsters. However, using biopolymers to flocculate microalgae has some disadvantages, including difficulty in recovering flocculants and in the solid-liquid separation after treatment processes.

To overcome these disadvantages, some researchers have used advanced technologies, e.g., magnetic nanoparticles, to separate microalgae from aqueous solutions. These technologies have attracted much attention from scholars. For instance, thanks to magnetization characteristics, magnetite $\left(\mathrm{Fe}_{2} \mathrm{O}_{3}\right)$ nanoparticles can adsorb microalgae

Nguyen et al. (2021). "Nopal cactus \& algae removal," BioResources 16(2), 3469-3493. 3470 
cells, then the cells can be taken out of the medium using a magnetic field. The use of magnetic nanoparticles in microalgae recovery can combine both flocculation and separation in a single-step process (Cerff et al. 2012). Xu et al. (2011) also indicated that magnetite nanoparticles seem to adsorb some microalgae species more easily than others. Adsorption can be improved by coating the nanoparticles with cationic polymers (Liu et al. 2009; Lim et al. 2012). An advantage of using magnetite nanoparticles for harvesting microalgae is that the nanoparticles can be recovered after harvesting and subsequently reused (Cerff et al. 2012). Biopolymers derived from amino compounds, e.g., chitin, chitosan, and their derivatives, have been found to be able to flocculate particulate inorganic or organic suspensions, dissolved organic substances, and microalgae (Renault et al. 2009). Pectin-based biopolymers are notorious for their application in the recovery of microalgae from eutrophication bodies (Vandamme et al. 2013). Besides, the isoelectric $\mathrm{pH}$ of magnetite material is about 6.0 (Sun et al. 1998). Thus, when chitosan or other biopolymers were prepared at suitably low $\mathrm{pH}$ ( $\mathrm{pH}$ of 4) with supplementation of magnetic particles, the $\mathrm{pH}$ is then raised to the neutral point, leading to effective deposition of biopolymer on to the magnetite surface. These results were exhibited through the decrease in electrokinetic potential (i.e., zeta potential) of biopolymer-modified flocculants, which contributed to the creation of van der Waals' attractive forces, facilitating aggregation and sedimentation of formed flocs (Lee et al. 2014).

In Vietnam, the Nopal cactus, which contains pectin in its gum, has been cultivated extensively along the central coastal region of Vietnam. They are abundant in the harsh lands that belong to sandy arid regions with no economic value. Thus, the use of the Nopal cactus (also known as the prickly pear cactus) to fabricate biopolymers, for the flocculation of microalgae from eutrophicated water bodies, will drastically reduce the cost of wastewater treatment due to the decrease in the amount of waste sludge production and usage of conventional flocculation chemicals.

Moreover, in order to overcome the disadvantages of biopolymers in terms of the flocculation of microalgae mentioned above, a composite nanomaterial, included $\mathrm{CoFe}_{2} \mathrm{O}_{4}$ magnetic nanoparticles as reinforcement in the biopolymer matrix, was fabricated from the extract of Nopal cactus. The microalgae recovery capability of the obtained materials was also tested in order to assess their potential in terms of microalgae recovery from aqueous solutions.

Thus, the aim of this study was to develop a green flocculant nanocomposite, derived from a mixture of pectin extracted from Nopal cactus and modified magnetic nanoparticles, in order to recover microalgae from aqueous solution. The characteristics of the synthesized materials were fully described. The factors affecting the material fabrication process and the microalgae flocculation efficiency were also systematically investigated. In addition, the recovery ability of the green flocculant via an external magnetic field after the treatment process was fully assessed. To achieve these objectives, the research was performed at a laboratory in the Industrial University of Ho Chi Minh City, Vietnam.

\section{EXPERIMENTAL}

\section{Chemicals}

The following reagents were used: cobalt (II) chloride $\left(\mathrm{CoCl}_{2} \cdot 6 \mathrm{H}_{2} \mathrm{O} 99 \%\right)$; iron (II) chloride $\left(\mathrm{FeCl}_{2} \cdot 4 \mathrm{H}_{2} \mathrm{O} 98 \%\right)$; sodium hydroxide $(\mathrm{NaOH} 96 \%)$; n-hexane (95\%); ethanol 
$\left(\mathrm{C}_{2} \mathrm{H}_{5} \mathrm{OH} 99.7 \%\right)$; and ammonium hydroxide $\left(\mathrm{NH}_{4} \mathrm{OH} 25 \%\right.$ to $\left.28 \%\right)$. These reagents were purchased from Merk (Darmstadt, Germany), while the sodium dodecyl sulfate (SDS greater than 80\%) was supplied by Acros Organics (Fair Lawn, NJ). All the reagents were used without any further purification. The Nopal cactus was collected from the Binh Dinh province, Vietnam, whereas the microalgae (Tetraselmis) used as target material was provided by the Institute for Environmental Science, Engineering, and Management (IESEM), at the Industrial University of Ho Chi Minh City (IUH).

\section{Pectin Extraction Procedure}

Pectin was extracted from Nopal cactus pads via the following procedure. First, the cleaned cactus pads were chopped into small pieces, ranging from $0.5 \mathrm{~cm}$ to $1.0 \mathrm{~cm}$, and then impregnated in water while adjusting the $\mathrm{pH}$ to 4 . The mixture was then boiled at a temperature of $80{ }^{\circ} \mathrm{C}$ for $20 \mathrm{~min}$ to eliminate any enzymes, which may hinder the subsequent extraction. Next, the mixture was cooled and adjusted to a $\mathrm{pH}$ of 7.5 using $\mathrm{NaOH}(0.1 \mathrm{~N})$ to reduce esterification groups. Then, the filtration was performed and the obtained solid was dispersed into $\mathrm{NaOH}(0.05 \mathrm{~N})$ for $2 \mathrm{~h}$ at an agitation speed of $500 \mathrm{rpm}$ and a $\mathrm{pH}$ of 12. From this, the filtration was performed again to obtain the filtrate which contained pectin. In the next step, the pectin was flocculated at a $\mathrm{pH}$ of 2 at a temperature of $5{ }^{\circ} \mathrm{C}$ overnight. Later, the post-flocculation solution was centrifuged at $5000 \mathrm{rpm}$ for 10 min to obtain the raw pectin. Finally, the raw pectin was washed with ethanol and rinsed with water several times. The sample was continuously dried to obtain pure pectin and stored in plastic bags for further usage.

\section{Fabrication of the Magnetic Nanoparticles and the Hydroxyl Modified Magnetic Nanoparticles}

The $\mathrm{CoFe}_{2} \mathrm{O}_{4}$ magnetic nanoparticles were fabricated via a co-precipitation procedure using sodium dodecyl sulphate (SDS) as a surfactant (Vadivel et al. 2015). At the beginning of the process, $250 \mathrm{~mL}$ of SDS solution $(9.35 \mathrm{~g}$ at $27.75 \mathrm{mmol})$ was quickly poured into $250 \mathrm{~mL}$ of a solution mixture that contained $\mathrm{CoCl}_{2} \cdot 6 \mathrm{H}_{2} \mathrm{O}(1.2 \mathrm{~g}$ at $5.0 \mathrm{mmol})$ and $\mathrm{FeCl}_{2} \cdot 4 \mathrm{H}_{2} \mathrm{O}(2.0 \mathrm{~g}$ at $10.0 \mathrm{mmol})$. The solution then was gently stirred at a temperature of $70{ }^{\circ} \mathrm{C} \pm 5^{\circ} \mathrm{C}$ for $30 \mathrm{~min}$. Subsequently, $500 \mathrm{~mL}$ of $\mathrm{NaOH} 0.75 \mathrm{M}$ was gradually poured into the reaction vessel. After $5 \mathrm{~h}$ of vigorous agitation at $1500 \mathrm{rpm}$ at a temperature of 70 ${ }^{\circ} \mathrm{C} \pm 5{ }^{\circ} \mathrm{C}$, the formed magnetic nanoparticles were collected via a strong magnet field and washed with water, ethanol, and n-hexane to remove the excess surfactant. Finally, the obtained precipitate $\left(\mathrm{CoFe}_{2} \mathrm{O}_{4}\right.$ magnetic nanoparticles (MNPs)) was air-dried overnight at room temperature (Zhang et al. 2011).

The above obtained magnetic nanoparticles were continuously modified to enrich the hydroxyl groups on their surface according to the following procedure. First, the MNPs were dispersed in a $350 \mathrm{~mL}$ mixture of ethanol and water at a ratio of 1:1 (v/v) with the aid of ultrasonic waves for $30 \mathrm{~min}$. Next, $35 \mathrm{~mL}$ of ammonium hydroxide $\left(\mathrm{NH}_{4} \mathrm{OH} 25 \%\right.$ to $28 \%$ ) was added, and the suspension was vigorously stirred at $120 \mathrm{rpm}$ and a temperature of $55{ }^{\circ} \mathrm{C}$ to $65{ }^{\circ} \mathrm{C}$ for $24 \mathrm{~h}$. Finally, the hydroxyl modified magnetic nanoparticles (MMNPs) were recovered via a strong magnet, washed with water and ethanol, and then air-dried overnight at room temperature (Zhang et al. 2011).

\section{Fabrication of the Nanocomposites (NCs)}

The highly negative zeta potential value of the algal culture necessitates use of a cationic flocculant. In this study, the nanocomposites formed from a mixture of pectin and

Nguyen et al. (2021). "Nopal cactus \& algae removal," BioResources 16(2), 3469-3493. 3472 
hydroxyl modified magnetic nanoparticles aimed to produce the cationic flocculant due to the interaction between positively charged $\mathrm{OH}$ groups-enriched $\mathrm{CoFe}_{2} \mathrm{O}_{4}$ nanoparticles with negatively charged pectin. The procedure for fabrication of the cationic flocculant was as follows: Firstly, the pectin solution and hydroxyl modified magnetic nanoparticles in a certain ratio were added into a beaker and ultra-sonicated at $\mathrm{pH}$ of 4.0 for a certain period of time. The solution was continuously ultra-sonicated and solution $\mathrm{pH}$ was adjusted to 7.0. Then, the formed NCs were collected using a strong magnet, washed with deionized water and ethanol, then air-dried and stored in plastic bag for next flocculation experiment of microalgae.

\section{Tetraselmis Microalgae and Culture Conditions}

The marine microalgae Tetraselmis was obtained from the Microalgae Laboratory of Institute for Environmental Science, Engineering, and Management (IESEM) at the Industrial University of Ho Chi Minh City (IUH). The growth procedure for Tetraselmis was modified from (Chatsungnoen and Chisti 2016). The microalgae cultivation procedure is described as follows:

The marine algae were grown in an artificial seawater medium containing $30 \mathrm{mg} / \mathrm{L}$ of a sodium metasilicate nonahydrate $\left(\mathrm{Na}_{2} \mathrm{SiO}_{3} \cdot 9 \mathrm{H}_{2} \mathrm{O}\right)$ solution. The artificial seawater was prepared by dissolving $40 \mathrm{~g}$ of sea salt in $1 \mathrm{~L}$ of distilled water. Next, the mixture was filtered through a Whatman GF-C $(0.45 \mu \mathrm{m})$ microfiber filter before use. The artificial seawater had a salinity of approximately 38.5 parts per thousand. Following that, a microalgae stock culture from liquid or solid agar media was transferred into $40 \mathrm{~mL}$ of BG11 (the growth medium compositions of microalgae), referenced from a study by Stanier et al. (1971), into $250 \mathrm{~mL}$ Erlenmeyer flasks. The flasks then were shaken at 120 $\mathrm{rpm}$ at room temperature $\left(25{ }^{\circ} \mathrm{C} \pm 2{ }^{\circ} \mathrm{C}\right)$ for approximately $20 \mathrm{~d}$ to $30 \mathrm{~d}$ to obtain a stable culture. The culture was continuously cultivated in $360 \mathrm{~mL}$ of BG11 in a $1.0 \mathrm{~L}$ beaker. The beakers were further incubated for $7 \mathrm{~d}$ to $14 \mathrm{~d}$ to multiply the microalgae. Next, approximately $400 \mathrm{~mL}$ of this inoculum was seeded in a $2.0 \mathrm{~L}$ beaker containing $1600 \mathrm{~mL}$ of fresh medium for $7 \mathrm{~d}$ to $14 \mathrm{~d}$. Later, the obtained culture was divided into $400 \mathrm{~mL}$ lots in five $2.0 \mathrm{~L}$ beakers, where each beaker consisted of $1600 \mathrm{~mL}$ of BG11 maintained at room temperature using continuous light from fluorescent lamp tubes $(40 \mathrm{~W})$. The harvest time of the Tetraselmis microalgae was over a post-inoculation period between $30 \mathrm{~d}$ and $55 \mathrm{~d}$ (the stationary phase). To conduct further experiments, the cultures were diluted with fresh medium to achieve the desired cell concentrations.

\section{Flocculation Experiment for Microalgae Recovery}

A Jar test apparatus (VE-20) was used for all experiments and had a six-spindle multiple stirrer unit with stainless-steel paddles. The microalgae flocculation procedure was carried out as follows: First, $50 \mathrm{~mL}$ of Tetraselmis algae solution, with a concentration of approximately 5 million cells per $\mathrm{mL}$ ( $1.5 \mathrm{~g} / \mathrm{L}$ dry weight $)$, was put into $150 \mathrm{~mL}$ beakers. Next, a certain amount of material (either MMNPs or NCs) was separately added into each beaker. Then, the mixture was rapidly stirred at $200 \mathrm{rpm}$ for $3 \mathrm{~min}$ (coagulation), followed by a slow stirring rate of $50 \mathrm{rpm}$ for $2 \mathrm{~min}$ (flocculation). Finally, the mixture was allowed to settle for $30 \mathrm{~min}$ and the suspension liquid containing algae was removed to determine the amount of algae via the counting method. 


\section{Analysis}

The characterization of the nanomaterials was carried out via X-ray diffraction (XRD) patterns recorded with a D8-Advance (Bruker, Billerica, MA) using monochromatic $\mathrm{Cu} \mathrm{K} \alpha$ radiation, and $2 \theta$ scanning ranges from $10^{\circ}$ to $80^{\circ}$ at a scanning rate of $2.25 \% \mathrm{~min}$. Infrared spectra, in the range of $400 \mathrm{~cm}^{-1}$ to $4000 \mathrm{~cm}^{-1}$, were measured via Fourier transform infrared (FTIR) spectrometer (TENSOR 27- Bruker, Billerica, MA). The morphology of the nanomaterials was observed via scanning electron microscopy (SEM) with a S-4800 (Hitachi, Tokyo, Japan). The transmission electron microscopy (TEM) studies were performed using a JEOL JEM 1400 transmission electron microscope at 100 $\mathrm{kV}$. The samples were dispersed on holey carbon grids for TEM observation. The magnetic properties were assessed via hysteresis loop, which was achieved using a PPMS 6000 vibrating sample magnetometer (VSM) at a temperature of $32{ }^{\circ} \mathrm{C}$. The samples were sonicated in dimethylformamide for 30 min before the measurements were performed. A Netzsch Thermoanalyzer STA 409 was used for the thermogravimetric analysis (TGA) with a heating rate of $10^{\circ} \mathrm{C} / \mathrm{min}$. The zeta potential was measured using Nano ZS, Malvern Inst., UK. The algal cell density (cells $/ \mathrm{mL}$ ) was measured using a hemocytometer under a light microscope with a suitable dilution of the cell suspension. A minimum of four measurements were made for each sample and the mean value of these measurements was used for calculations (Guillard and Sieracki 2005).

The results were determined according to Eq. 1,

$$
\text { cells } / \mathrm{mL}=\frac{\text { the counted microalgae cells }}{\text { number of squares }} * 4.000 .000 * \text { dilution rate }
$$

Dry weight of microalgae is the weight of the product the water removed. In this study, dry weight of microalgae products was calculated from standard curve (Cell wet weight in $\mathrm{g} / \mathrm{L}$ versus cell dry weight in $\mathrm{g} / \mathrm{L}$ ).

\section{RESULTS AND DISCUSSION}

\section{The Effect of the Solution pH on Pectin Extraction Process}

The pectin extraction process included three stages: enzyme reduction, pectin separation, and pectin collection. The experiments for investigating the effect of the solution $\mathrm{pH}$ on enzyme extraction were conducted at various solution $\mathrm{pH}$ values, which ranged from 1.0 to 5.0 for enzyme reduction, 7.0 to 14.0 for pectin separation, and 1.0 and 5.0 for the pectin collection process. In all experiments, the amount of Nopal cactus was fixed at $100 \mathrm{~g}$ (wet weight), and the extraction temperature was $80^{\circ} \mathrm{C}$.

The obtained results are presented in Fig. 1. All pectin extraction stages were strongly dependent on the $\mathrm{pH}$ of the medium. It can be seen from Fig. 1a that the recovery efficiency of pectin increased from $0.52 \%$ to $1.57 \%$ as the $\mathrm{pH}$ increased from 1.0 to 4.0 ; however, this trend decreased when the $\mathrm{pH}$ was further increased. The recovery efficiency of pectin reached its maximum at a $\mathrm{pH}$ of 4 . This can be explained by the fact that the higher $\mathrm{pH}$ value led to a higher solubility of pectin in water, thus a lower pectin recovery efficiency was reached. When the $\mathrm{pH}$ of the solution was greater than 4 , the pectin extraction efficiency decreased due to a drop in acidity, which caused a decrease in enzyme reduction ability. Additionally, when the acidity decreased, the transfer of the $-\mathrm{COOCH}_{3}$ functional group with weak polarization into a $-\mathrm{COO}^{-}$functional group with stronger polarization was also affected, which led to a decrease in the amount of obtained pectin.

Nguyen et al. (2021). "Nopal cactus \& algae removal," BioResources 16(2), 3469-3493. 3474 
The results agreed with previous studies by Joye and Luzio (2000) and Srivastava and Malviya (2011).

Figure $1 \mathrm{~b}$ indicates that the pectin separation efficiency increased when the $\mathrm{pH}$ of the solution was increased and reached its maximum at a $\mathrm{pH}$ of 10 . However, when the $\mathrm{pH}$ was increased past 10, there was a downward trend in the pectin separation efficiency. The results can be explained by the fact that in a pectin separation medium with a $\mathrm{pH}$ of less than 10, the weak polarization functional groups are not completely transferred into a dissolving form, thus causing a decrease in the total obtained pectin content. In addition, when the $\mathrm{pH}$ was greater than 10 , the polysaccharides were degraded into monosaccharides or oligomers that were easily dissolved in water, thus the total obtained pectin amount was also drastically decreased (Joye and Luzio 2000; Srivastava and Malviya 2011; Muazu et al. 2014).
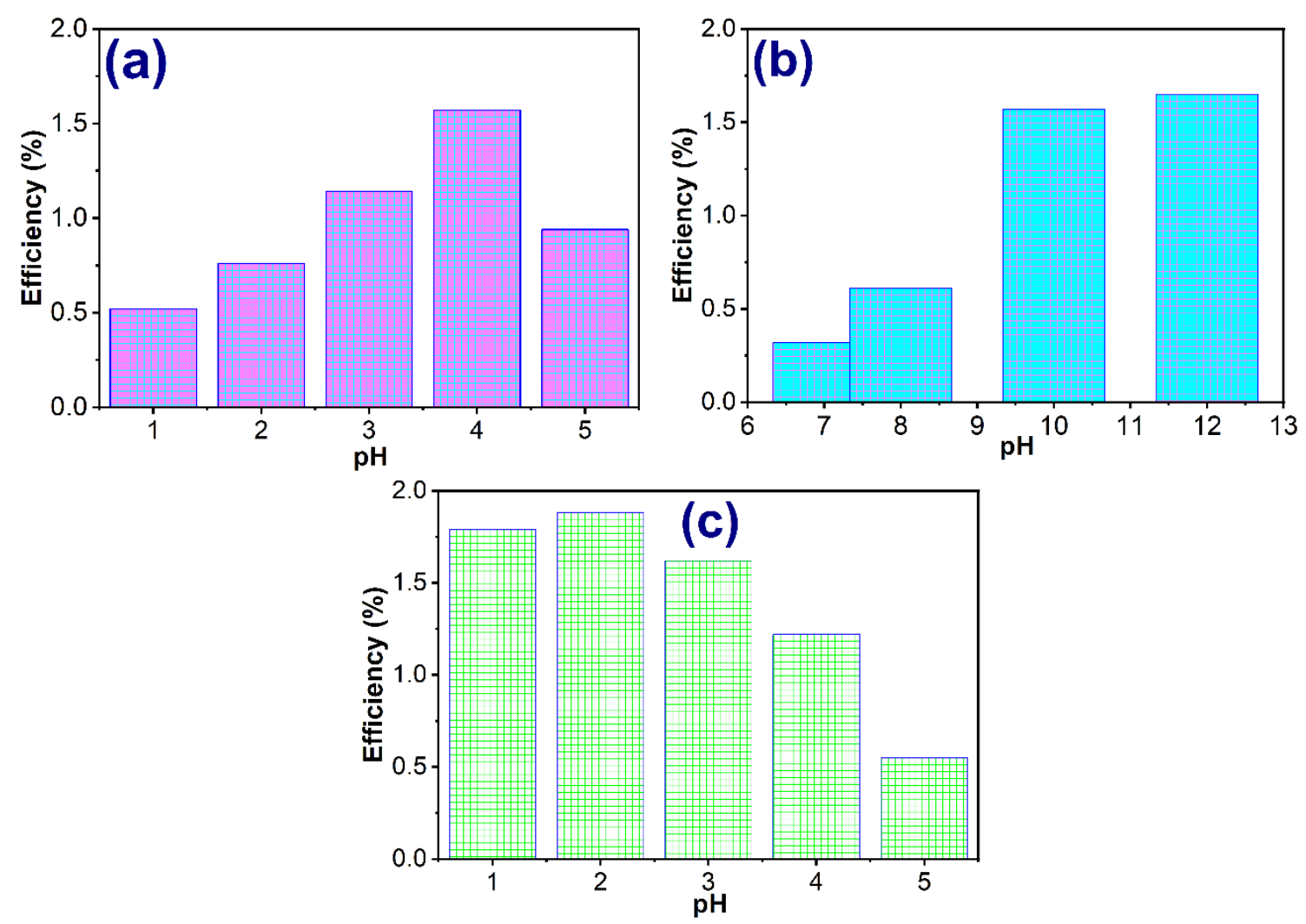

Fig. 1. Effects of the pH of the solution on the enzyme extraction process: (a) the enzyme reduction process; (b) the pectin separation process; and (c) the pectin collection process

The effects of the $\mathrm{pH}$ of the solution on the pectin collection efficiency are presented in Fig. 1c. It is shown that the pectin collection efficiency was maximized $(1.88 \%)$ at $\mathrm{pH} 2$. From Fig. 1c, it can be seen that the higher the $\mathrm{pH}$, the lower the pectin collection efficiency. The pectin collection efficiency decreased from 1.88 to 0.53 as the solution $\mathrm{pH}$ increased from 2.0 to 5.0. This could be due to the fact that the reversion ability of carboxyl groups in weak acid conditions was difficult to achieve, which triggered a decrease in the obtained pectin content of the precipitated matter. Similar results were also obtained by Joye and Luzio (2000), Srivastava and Malviya (2011), and Muazu et al. (2014). 


\section{The Effect of Chemical Agents on the Pectin Extraction Process}

Determining the effect of chemical agents on the pectin extraction process was conducted as follows: for the enzyme reduction stage, the used acid agents were $\mathrm{HCl}$, $\mathrm{H}_{2} \mathrm{SO}_{4}, \mathrm{HNO}_{3}$, acetic, and citric acid $(0.1 \mathrm{~N})$, with a solution $\mathrm{pH}$ of 2 at a separation time of $10 \mathrm{~h}$; for the pectin separation stage, the used separation agents consisted of $\mathrm{KOH}, \mathrm{NaOH}$, $\mathrm{Ca}(\mathrm{OH})_{2}, \mathrm{~K}_{2} \mathrm{CO}_{3}$, and $\mathrm{Na}_{2} \mathrm{CO}_{3}(0.1 \mathrm{~N})$, at a $\mathrm{pH}$ of 10 and a separation time of $5 \mathrm{~h}$; and for the pectin collection stage, the used acid agent was hydrochloric acid $(\mathrm{HCl})$ with a concentration ranging from $1.0 \mathrm{~mol} / \mathrm{L}$ to $4.0 \mathrm{~mol} / \mathrm{L}$ at a $\mathrm{pH}$ of 2.0 and a pectin collection time of $5 \mathrm{~h}$. The obtained results are demonstrated in Fig. 2.

Figure $2 \mathrm{a}$ shows that using $\mathrm{HCl}$ acid agent yielded the highest pectin collection efficiency $\left(1.57 \%\right.$ ), with the yield decreasing in the following order: $\mathrm{H}_{2} \mathrm{SO}_{4}$ was greater than $\mathrm{C}_{6} \mathrm{H}_{8} \mathrm{O}_{7}$, which was greater than $\mathrm{HNO}_{3}$, which was greater than $\mathrm{CH}_{3} \mathrm{COOH}$. The strong oxidation agents, e.g., $\mathrm{H}_{2} \mathrm{SO}_{4}$ and $\mathrm{HNO}_{3}$, made some functional groups which could oxidize or hydrolyze polysaccharides into monosaccharides, which easily dissolved in water, thus amount of obtained pectin would be decreased in the next stages. Meanwhile, when organic acids, e.g., acetic acid and citric acid, were used, they provided either $\mathrm{H}^{+}$ions that degraded enzymes or played the role of an emulsifier, which decreased the pectin separation ability from the cactus samples (Muazu et al. 2014).

Figure $2 \mathrm{~b}$ shows the effects of various chemical agents on the pectin separation process. Among the used agents, $\mathrm{NaOH}$ yielded the highest pectin separation efficiency $\left(1.88 \%\right.$ ), followed by $\mathrm{KOH}, \mathrm{Ca}(\mathrm{OH})_{2}, \mathrm{~K}_{2} \mathrm{CO}_{3}$, and $\mathrm{Na}_{2} \mathrm{CO}_{3}$, with efficiencies of $1.68 \%$, $1.39 \%, 1.28 \%$, and $1.15 \%$, respectively. These results could be explained by that fact that $\mathrm{NaOH}$ was a strong base, which caused a saponification reaction to convert favorable functional groups $\left(-\mathrm{OOCH}_{3}\right.$ and $\left.-\mathrm{COOH}\right)$ into $-\mathrm{COONa}$; thus, the pectin was easily dissolved in water. In the case of $\mathrm{KOH}$, the radius of the $\mathrm{K}^{+}$ions were greater than the radius of the $\mathrm{Na}^{+}$ions, which had slight effect on the saponification reaction of $\mathrm{KOH}$; this led to a marginal decrease in the pectin separation efficiency. However, the pectin separation efficiency using $\mathrm{NaOH}$ and $\mathrm{KOH}$ had no insignificant difference. Moreover, $\mathrm{Ca}(\mathrm{OH})_{2}$ is a strong base and caused pectin precipitation, which led to product loss. Meanwhile, both $\mathrm{K}_{2} \mathrm{CO}_{3}$, and $\mathrm{Na}_{2} \mathrm{CO}_{3}$ were weak bases, which resulted in poor saponification reactions and low pectin separation efficiency. These results were similar to previous studies by Joye and Luzio (2000), Srivastava and Malviya (2011), and Muazu et al. (2014). In addition, this study also determined the optimum pectin separation time was 5 hours (data not shown).

The effects of the changes in the concentration of the acid agent on the pectin collection process are presented in Fig. 2c. As shown in Fig. 2c, the obtained maximum amount of pectin $(1.88 \%)$ occurred when using $\mathrm{HCl}$ at a concentration of $1.0 \mathrm{~mol} / \mathrm{L}$. This trend gradually decreased as the acid concentration increased. The reason for this step, after using strong base agent $(\mathrm{NaOH})$ for separation of pectin, was to reconstitute the acid functional groups of the pectin. If the acid concentration was too high (low $\mathrm{pH}$ ), the pectin was easily hydrolyzed into other products, which led to a decrease in the amount of precipitated pectin. Similar results were also found in recent publications by Atkinson et al. (2002), Goycoolea and Cárdenas (2003), and Atkinson et al. (2008). At an acid concentration of $0.5 \mathrm{~mol} / \mathrm{L}$, the pectin collection efficiency was $1.63 \%$, which was lower than the efficiency using $1.0 \mathrm{~mol} / \mathrm{L}$ of acid. This might be due to the low acid concentration, which was not enough to ensure full precipitation of the available pectin in the medium.

Nguyen et al. (2021). "Nopal cactus \& algae removal," BioResources 16(2), 3469-3493. 3476 
Table 1. Optimal Parameters and Conditions for Pectin Extraction from Nopal Cactus

\begin{tabular}{|c|c|c|c|}
\hline Parameters & $\begin{array}{c}\text { Enzyme Reduction } \\
\text { Medium }\end{array}$ & Pectin Separation & Pectin Collection \\
\hline $\mathrm{pH}$ & 4.0 & 10.0 & 2.0 \\
\hline Acid agent & $\mathrm{HCl}$ & - & - \\
\hline Time (h) & - & $5.0 \mathrm{~h}$ & - \\
\hline Separation agent & - & $\mathrm{NaOH}$ & - \\
\hline Acid concentration (mol/L) & - & - & $1.0 \mathrm{~mol} / \mathrm{L}$ \\
\hline
\end{tabular}
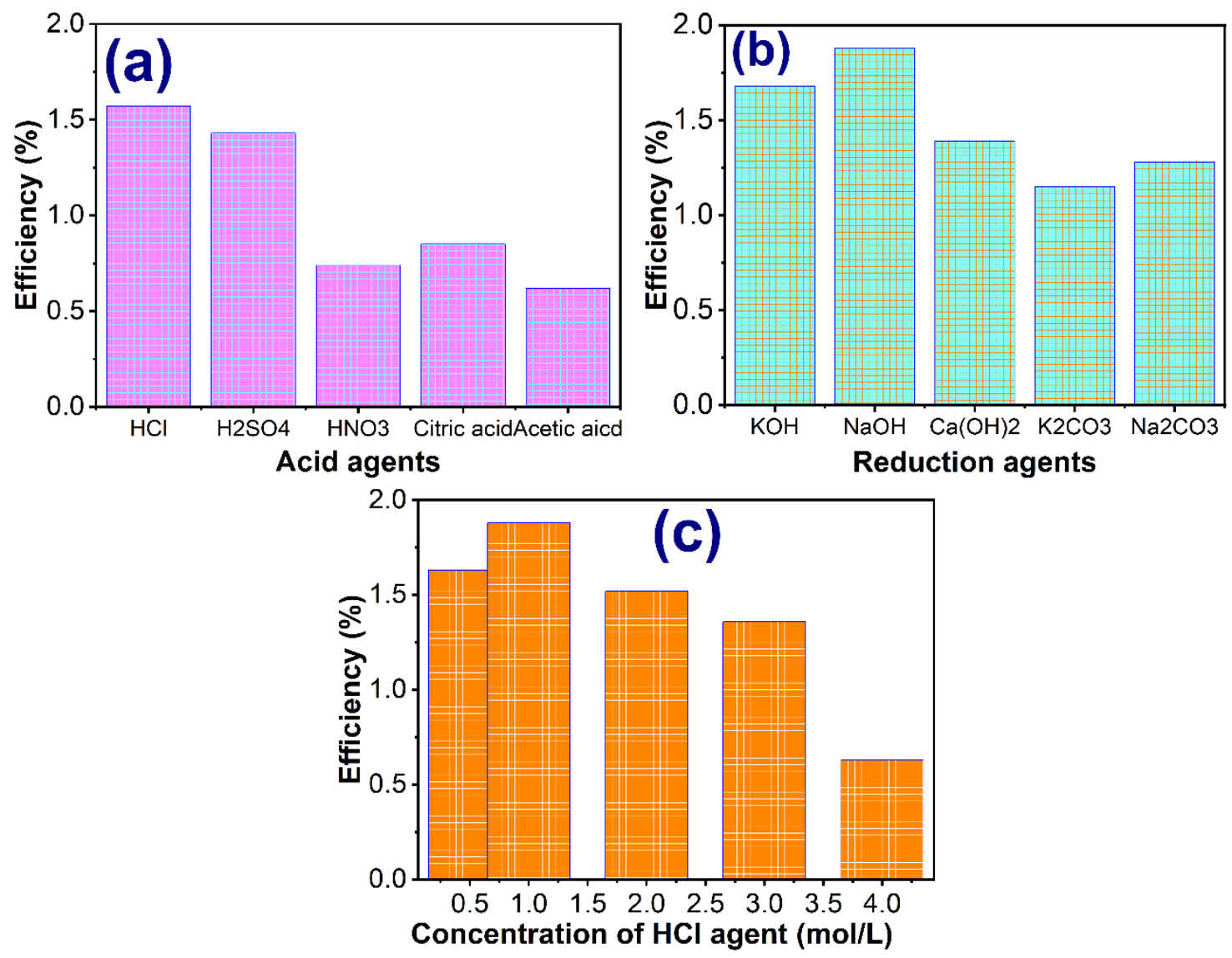

Fig. 2. Effect of the chemical agents on the pectin extraction efficiency: (a) the pectin reduction; (b) the pectin separation; and (c) the pectin collection

To summarize, the optimal parameters and conditions for the pectin extraction process of Nopal cactus are listed in Table 1.

\section{Characteristics of the Obtained Pectin}

The FTIR data of the obtained pectin is shown in Fig. 3. It is apparent that there was a strong fluctuation at $3427.1 \mathrm{~cm}^{-1}$, which was the characteristic oscillation for the $\mathrm{OH}$ group. Peaks at $1622.5 \mathrm{~cm}^{-1}$ and $1428.2 \mathrm{~cm}^{-1}$ represented the $\mathrm{C}=\mathrm{O}$ group of COO- in asymmetric and symmetrical structures, respectively (Goycoolea and Cárdenas 2003; Atkinson et al. 2008). 

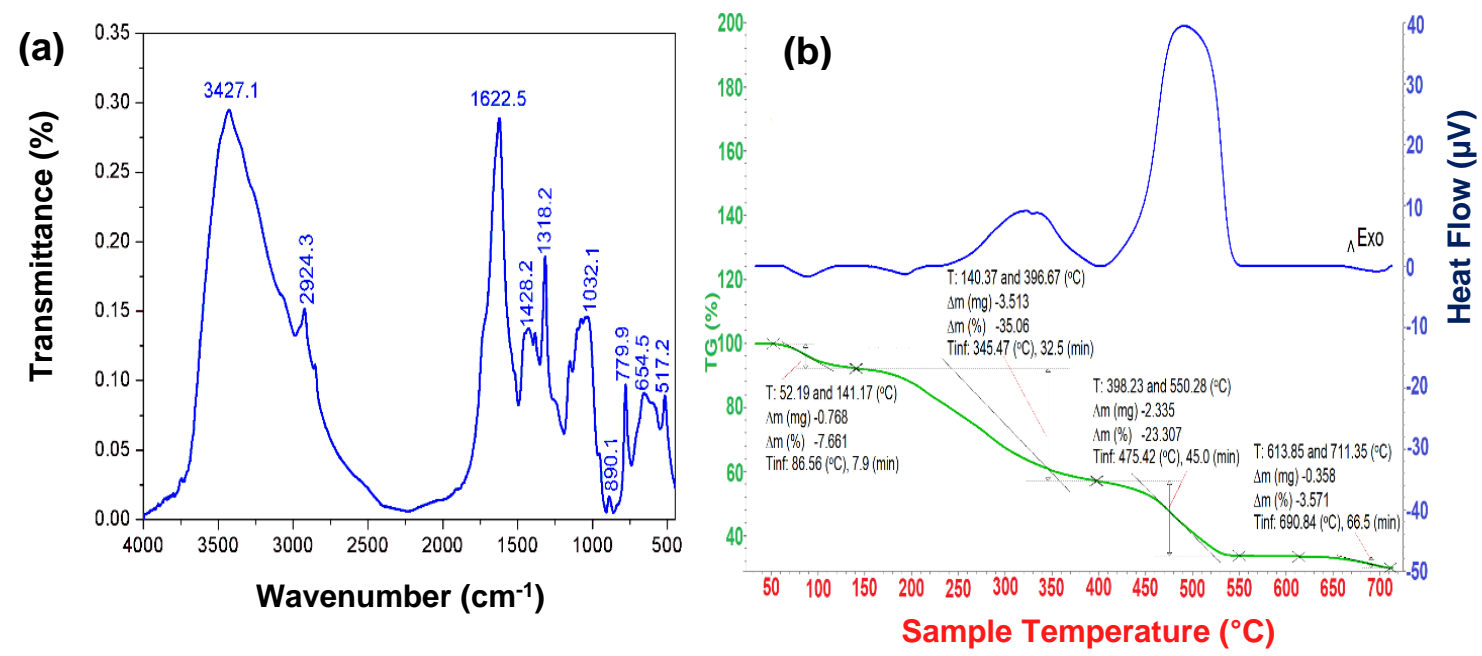

Fig. 3. FTIR and TG/DSC of the Nopal cactus-derived pectin: (a) FTIR; and (b) TG/DSC

The TG-DSC analysis results are shown in Fig. 3b. It is clear from the graph at temperatures ranging from 52.2 to $141.2{ }^{\circ} \mathrm{C}$, there was a drop in weight of $7.66 \%$. The corresponding endothermic peak appeared at $86.6{ }^{\circ} \mathrm{C}$, which indicated that the pectin sample dehydrated into a free form and formation of hydrogen bond at this temperature range (Atkinson et al. 2008; Kazemzadeh et al. 2013). Conversely, at temperatures ranging from 140.4 to $396.7^{\circ} \mathrm{C}$, the corresponding exothermal peak at $345.5^{\circ} \mathrm{C}$ appeared, so both the pectin and the organic functional groups on the surface of the pectin considerably decomposed, and the sample volume decreased to $35.1 \%$. At temperatures ranging from 398.2 to $550.3{ }^{\circ} \mathrm{C}$, a strongly exothermal peak was found in the pectin sample; the exothermal peak occurred at a temperature of $475.4{ }^{\circ} \mathrm{C}$, and the volume of the sample decreased by $23.3 \%$. At temperatures ranging from $613.8^{\circ} \mathrm{C}$ to $711.4{ }^{\circ} \mathrm{C}$, there was minor loss in the sample weight (decreased by $3.57 \%$ ), which indicated that the pectin sample was neither exothermal nor endothermic (Atkinson et al. 2008; Kazemzadeh et al. 2013). From the results of the TG/DSC analysis, it can be concluded that the pectin sample cannot be easily decomposed at room temperature.

\section{Characteristics of the Hydroxyl Modified Magnetic Nanoparticles (MMNPs)}

The $\mathrm{CoFe}_{2} \mathrm{O}_{4}$ magnetic nanoparticles were synthesized via the co-precipitation method with the support of surfactants (SDS), then modified with $\mathrm{NaOH}$ to enrich the $-\mathrm{OH}$ group on the surface of the MNPs (Bui et al. 2011; Ramazani et al. 2015; Vadivel et al. 2015). The SEM and TEM images and the XRD of modified magnetic nanoparticles are shown in Fig. 1S. The SEM and TEM data in Fig. 1Sa show that the synthesized $\mathrm{CoFe}_{2} \mathrm{O}_{4}$ magnetic nanoparticles had a uniform particle size with diameter of 30 to $40 \mathrm{~nm}$. However, it can be seen from the SEM image that there was a group of agglomerated particles in the MMNP structure; this agglomeration was more clearly observed in the TEM images with a magnetic nanoparticle size of 5 to $10 \mathrm{~nm}$ in diameter. It should be noted that almost all the oxide particles, regardless of composition, aggregated on the TEM mesh, but this did not mean that the magnetic nanoparticles were similarly aggregated in solution (Phan and Jones 2006). The crystal structure of the synthesized magnetic nanoparticles was investigated via the X-ray diffraction (XRD) method. The results are shown in Fig. $1 \mathrm{Sb}$. From the standardized diffraction pattern data (JCPDS card, No. 22-1086), it can be

Nguyen et al. (2021). "Nopal cactus \& algae removal," BioResources 16(2), 3469-3493. 3478 
confirmed that the synthesized $\mathrm{CoFe}_{2} \mathrm{O}_{4}$ magnetic nanoparticles had a cubic spinel structure. This result was consistent with previous studies on $\mathrm{CoFe}_{2} \mathrm{O}_{4}$ magnetic materials (Kim et al. 2003; Bui et al. 2011; Zieliska-Jurek et al. 2012; Tiến and Tuyết 2015). The magnetic characteristics of the MMNPs were investigated via VSM and the surface group characteristics of the MMNPs were measured via FTIR. The results were shown in Fig. 4.

In previous studies by Can et al. (2009) and Gandha et al. (2015), magnetic nanoparticles were dispersed in a DMF solvent to investigate their magnetic properties at a temperature of $305 \mathrm{~K}$. Under the influence of an external magnetic field, the nanoparticles were magnetized to reach a magnetic saturation equal to conventional magnetic materials. However, unlike conventional magnetic materials with residual magnetic phenomena, when the external magnetic value of the $\mathrm{CoFe}_{2} \mathrm{O}_{4}$ magnetic nanoparticles reached zero, the magnetization of the sample was also annihilated. Due to this property, the magnetic nanoparticles were uniformly dispersed in the solution, which drastically increased the contact surface area between the nanoparticles and pollutants, thus making them more easily recovered via separation from the mixture by the external magnetic field. The VSM results of the $\mathrm{CoFe}_{2} \mathrm{O}_{4}$ nanoparticles (Fig. 4b) showed that the saturation of the $\mathrm{CoFe}_{2} \mathrm{O}_{4}$ nanoparticles was $32 \mathrm{emu} / \mathrm{g}$, with the magnetic resistance reaching 399 Oe. This meant that the synthesized material possessed a low coercive velocity; thus, it can be considered a soft magnetic material and super-paramagnetic, implying that it can be easily magnetized and demagnetized. With a magnetic saturation of $32 \mathrm{emu} / \mathrm{g}$, along with a nanometre particle size, the synthesized materials had super-paramagnetic properties and therefore they were considerately dispersed in solution and were easily recovered via magnetic field after the flocculation of microalgae.

The FTIR spectrum of the MMNPs (as shown in Fig. 4a) showed Fe-O bonding valence oscillation absorption peaks at $595.8 \mathrm{~cm}^{-1}$, O-H bonding from the hydroxyl group on the surface of the MMNPs with a valence oscillation peak occurring at approximately $3418.4 \mathrm{~cm}^{-1}$, and the presence of strain variation at $1620.5 \mathrm{~cm}^{-1}$. This confirmed that the MNPs were successfully modified with an enrichment of $\mathrm{OH}$ functional groups and the $\mathrm{OH}$ groups were fully loaded on the surface of the MMNPs (Yazid et al. 2019).
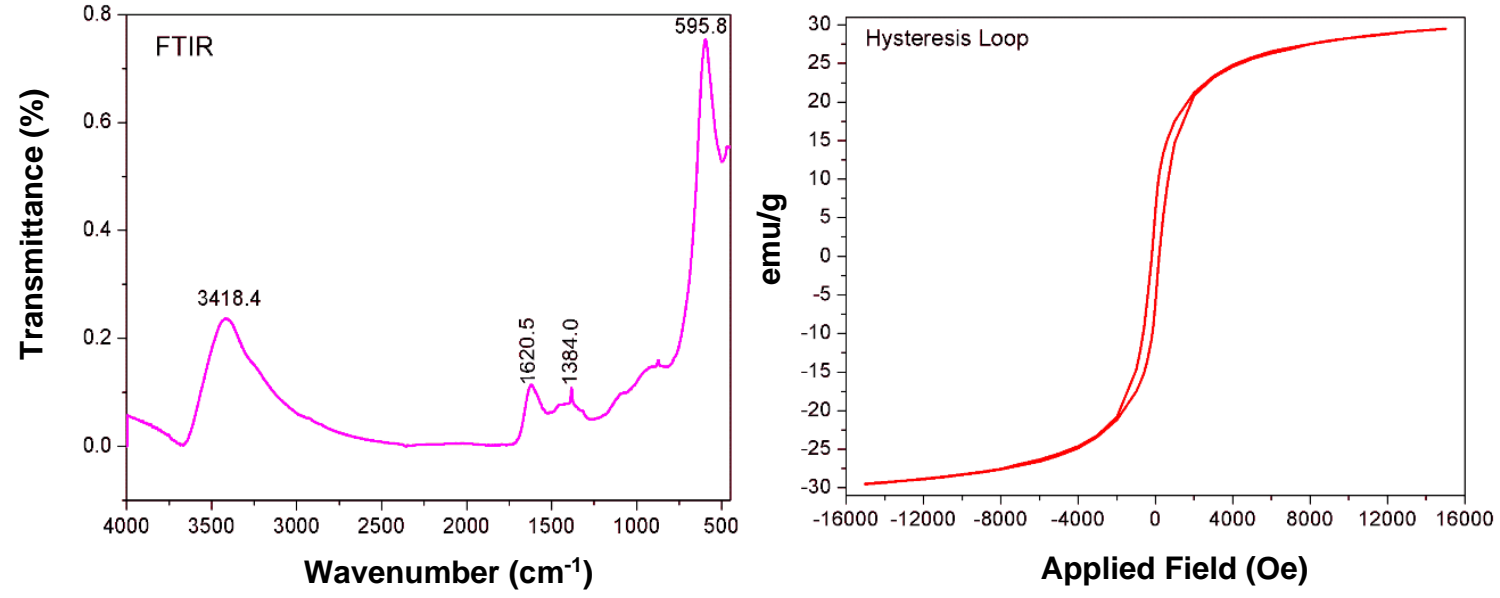

Fig. 4. (a) FTIR; and (b) the magnetic hysteresis curve of the MMNPs

The $\mathrm{CoFe}_{2} \mathrm{O}_{4}$ magnetic nanoparticles were analyzed via TG-DSC to assess the heat stability. The results shown in Fig. 5 illustrated that in the temperature range of $48.8{ }^{\circ} \mathrm{C}$ to

Nguyen et al. (2021). "Nopal cactus \& algae removal," BioResources 16(2), 3469-3493. 3479 
$154.7^{\circ} \mathrm{C}$, the mass reduction was $2.23 \%$, which corresponded to the endothermic peak at $77.6^{\circ} \mathrm{C}$. This occurred since the magnetic nanoparticles were not in free-form and formed hydrogen bonds with water. Similarly, at a temperature range of $155.7{ }^{\circ} \mathrm{C}$ to $434.7{ }^{\circ} \mathrm{C}$, a corresponding exothermal peak appeared at a temperature of $242.3{ }^{\circ} \mathrm{C}$ in the MMNPs; the magnetic nanoparticle mass decreased by $3.30 \%$. In comparison with pectin at the same temperature range, there was a drastic loss (35.1\%) in the pectin mass (Fig. 3b). At the temperature range of $435.0{ }^{\circ} \mathrm{C}$ to $706.9{ }^{\circ} \mathrm{C}$, the MMNPs contained both the weak exothermal and endothermic peaks and the sample volume only decreased by $1.41 \%$. From the analysis results, with the same temperature ranges, it was clear that the remaining sample weight of the MMNPs was greater than 93\%, while the remaining mass of pectin was only $30.4 \%$, which indicated that the MMNPs were more heat resistant than pectin.

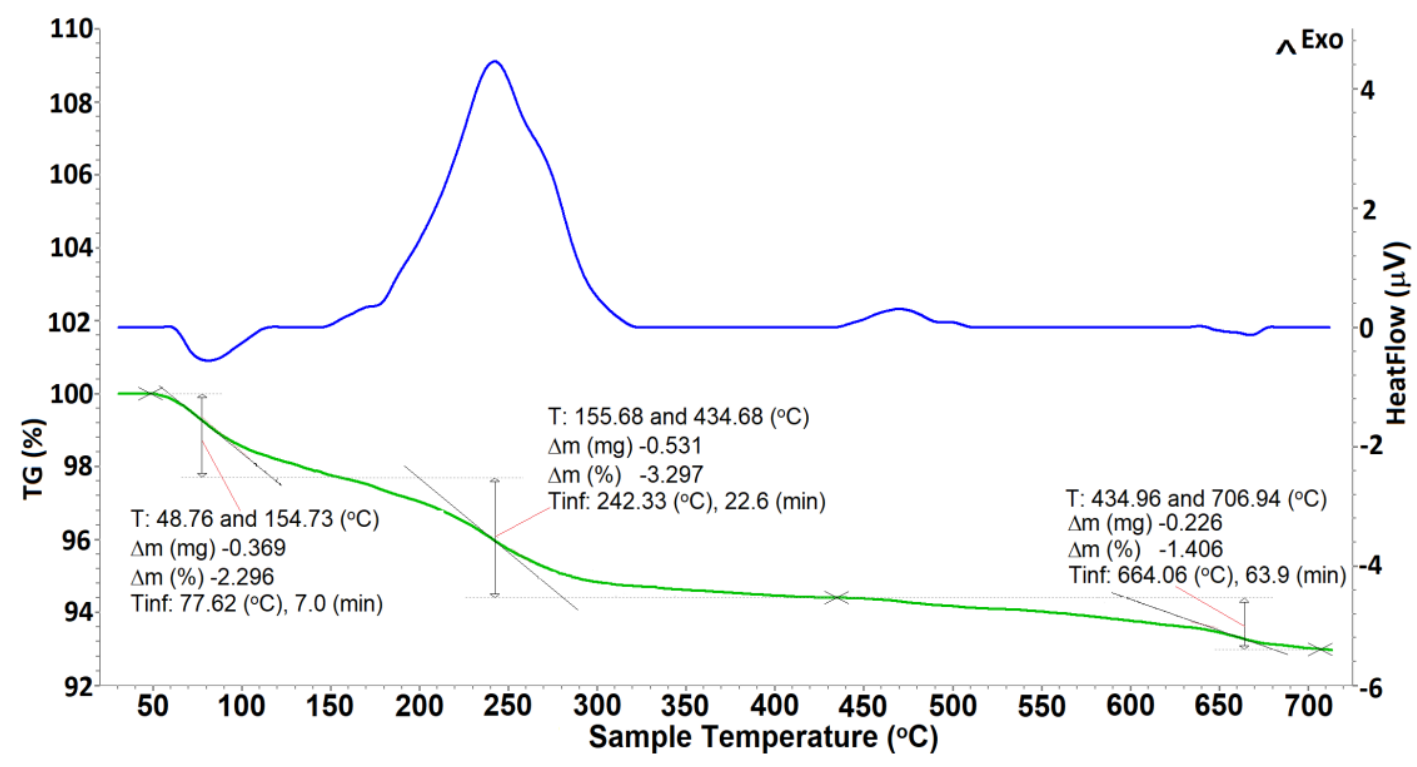

Fig. 5. TG/DSC analysis of the MMNPs

The zeta potential data were used to evaluate the effects of nanoparticles in the colloidal phase and their aggregates. High absolute values of zeta potentials indicate stability of nanoparticles in suspension. The zeta potential data of MMNPs are presented in Fig. 6. What stands out from the data in the figure is that the zeta potential value of MMNPs was high throughout the studied ranges of $\mathrm{pH}$. Thus, the synthesized OH groupenriched magnetic nanoparticles were dispersed in water due to the large electrostatic repulsive forces between the particles. The isoelectric point of MMNPs was 6.7, while the zeta potential value of pectin ranged from -6 to $-50 \mathrm{mV}$. Therefore, a suitable system was obtained when the pectin was combined at a $\mathrm{pH}$ of 4 with MMNPs, which had a sufficient positive ionic charge at $\mathrm{pH}$ of 4 to keep them stable and then increase to isoelectric point. As a result, the zeta potential approaches zero, and the microalgae particles are destabilized, leading to the beneficial flocculation of negatively charged microalgae. Moreover, the composite process enhanced the growth in flocculant's size to interact with microalgae for production of larger flocs, triggering easy in separation microalgae from solution by gravity sedimentation. Similar results were obtained by Yang et al. (2013) using pectin modified by etherification and polyaluminum chloride (PAC) to produce the cationic flocculant for flocculation of anion $\mathrm{Cr}_{2} \mathrm{O}_{7}{ }^{2-}$ through electronic interaction. This 
was attributed to the fact that the carboxyl groups in pectin would be in the carboxylate form, leading to a drop in zeta potential, with the formation of bridges that would bind the colloids together.

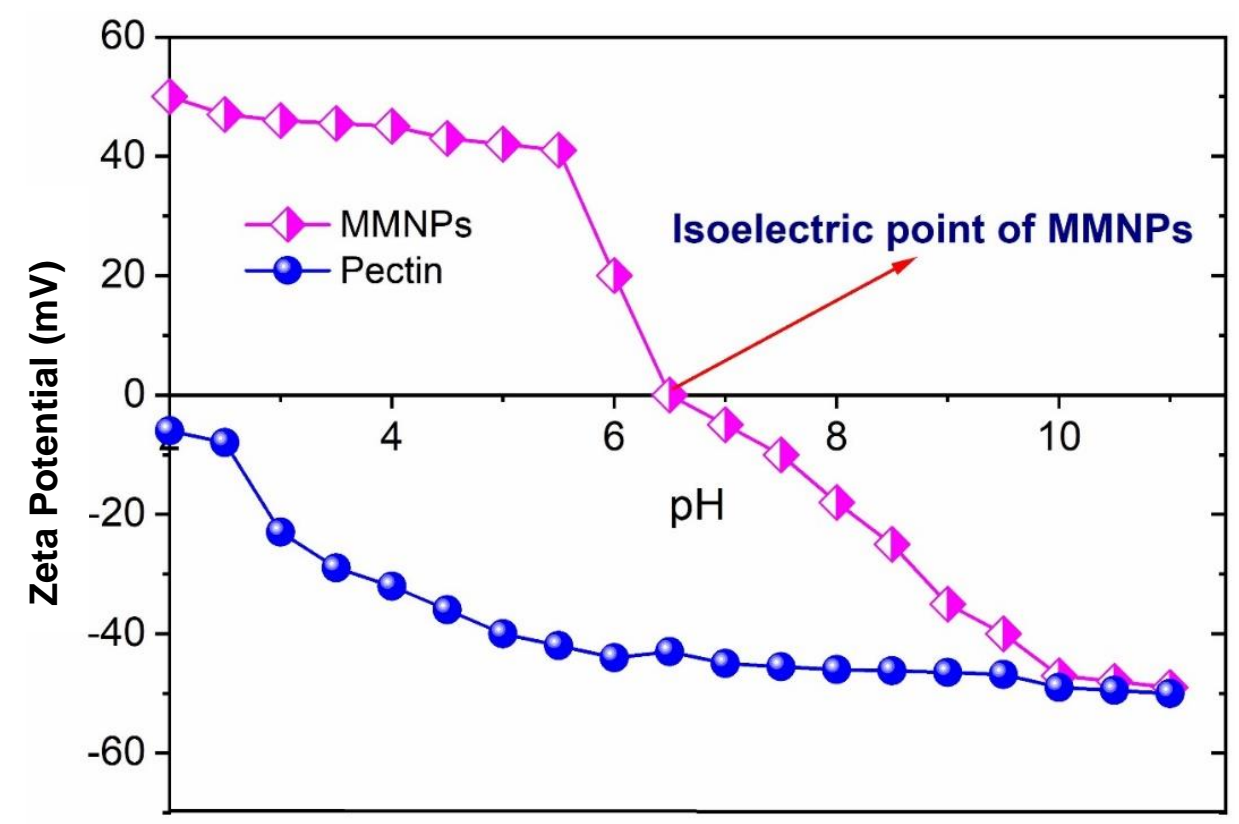

Fig. 6. Electrokinetic properties of MMNPs

\section{The Effect of Various Hydroxyl Modified Magnetic Nanoparticle (MMNP) and Nanoparticle (NP) Ratios (w/w) on Nanocomposite (NCs) Fabrication}

To investigate the effect of the MMNP to NP ratio on the nanocomposite fabrication process, the experiments were conducted at a sonication capacity of 50\% and a sonication time of 10 min with various ratios of MMNPs to NPs ( 1 to 1,1 to 2,1 to 3,1 to 4 , and 1 to $5(w / w))$.

The results in Fig. 7 revealed that as the pectin content was increased from a 1 to 2 ratio to a 1 to 5 ratio of MMNPs to NPs, the synthesized composite content increased, but the magnetization sharply decreased. When the ratio of the magnetic and pectin nanoparticles was equal, the magnetization was highest, but the obtained composite content was lowest. The reason for this was that the pectin was not sufficient for completely associating with the empty sites on the surface of the magnetic nanoparticles. Thus, the pectin dissolved into the water after the washing process. When the pectin content was increased by 5 times, all the magnetic nanoparticles were completely associated with pectin, so the amount of obtained composite was the highest, while the magnetization decreased due to the resistance of pectin. The results of this study were analogous with previously published studies by Yuan et al. (2010), Zhang et al. (2011), and Namanga et al. (2013). 


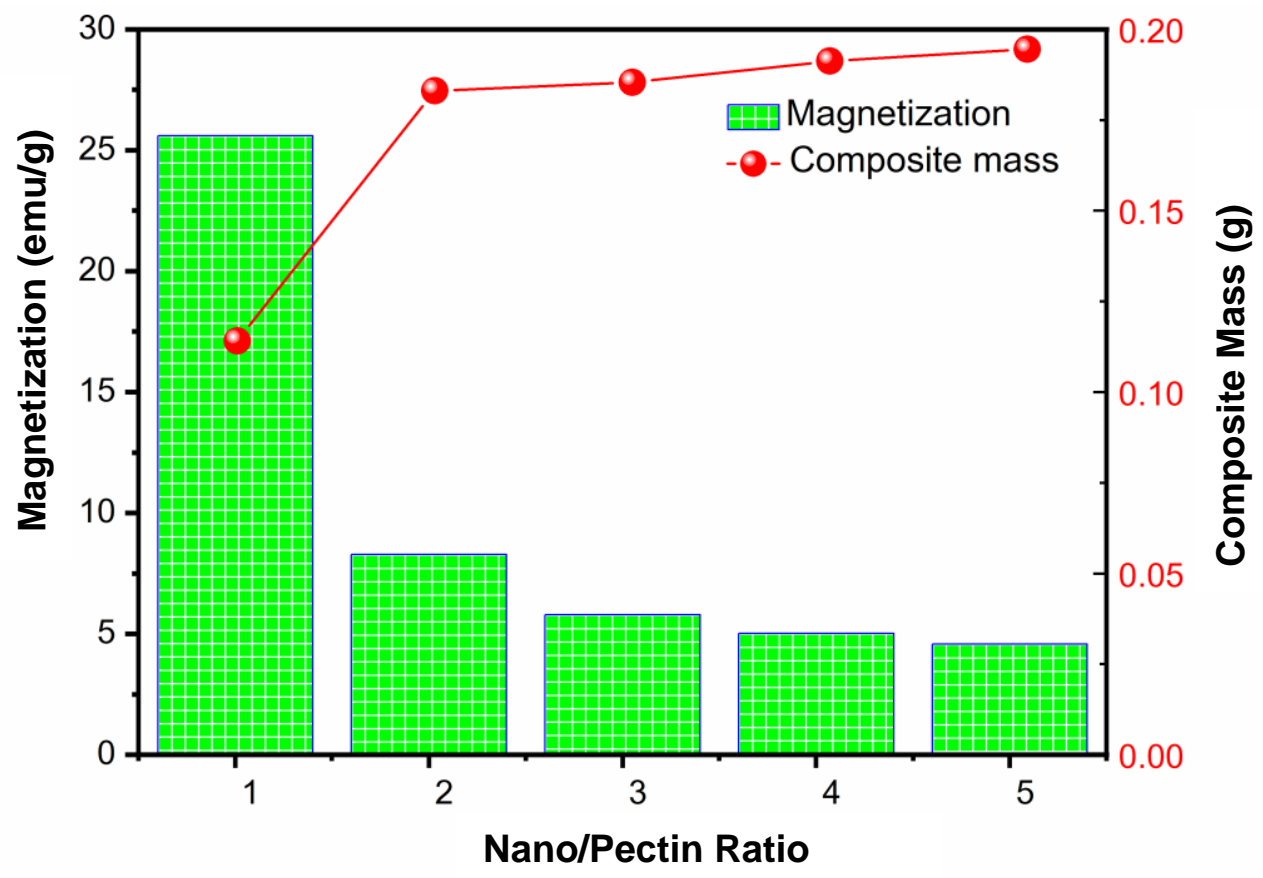

Fig. 7. The obtained amount of NCs and the magnetization of the NCs at various MMNPs to NPs ratios

From an economic perspective, although the magnetic nanoparticles made composite recovery easier, the synthesis of magnetic nanoparticles was expensive and produced a large amount of waste sludge. Additionally, the role of pectin in during the flocculation of microalgae was better than that of the magnetic nanoparticles. Due to the above reasons, the next experiments should be conducted at a MMNPs to NPs ratio of 1 to 3.

\section{The Effect of the Sonication Time and Capacity on Nanocomposite Fabrication}

The experiments to investigate the effect of the sonication time on the NC fabrication process were carried out at a sonication capacity of 50\% and a MMNP to NP ratio of 1 to 3 , while the experiments to investigate the effect of the sonication capacity on the NC fabrication process were performed at a MMNP to NP ratio of 1 to 3, with varying sonication capacities ranging from $30 \%$ to $70 \%$ at a sonication time of $20 \mathrm{~min}$. The results in Fig. 8a indicated an increase in sonication time led to an increase in obtained composite content and a decrease in the magnetization of the NC. These results could be attributed to a rise in energy supplied to the reaction when the ultrasonic time was increased. In addition, the dispersion, as well as the collision between the pectin particles and magnetic nanoparticles, increased, which resulted in the formation of linkages between the NPs and MNPs. When the NP to MMNP ratio increased, the magnetization decreased, due to the resistance property of the pectin. Moreover, an increase in the NP to MMNP ratio also facilitated the linkage between the magnetic nanoparticles and pectin molecules, leading to a decline in the magnetization saturation. At an ultrasonic time of $20 \mathrm{~min}$, the obtained NC content was slightly lower compared to the 40 min sonication time, but the magnetization was much higher, thus an ultrasonic time of 20 min was chosen for the following experiments. 

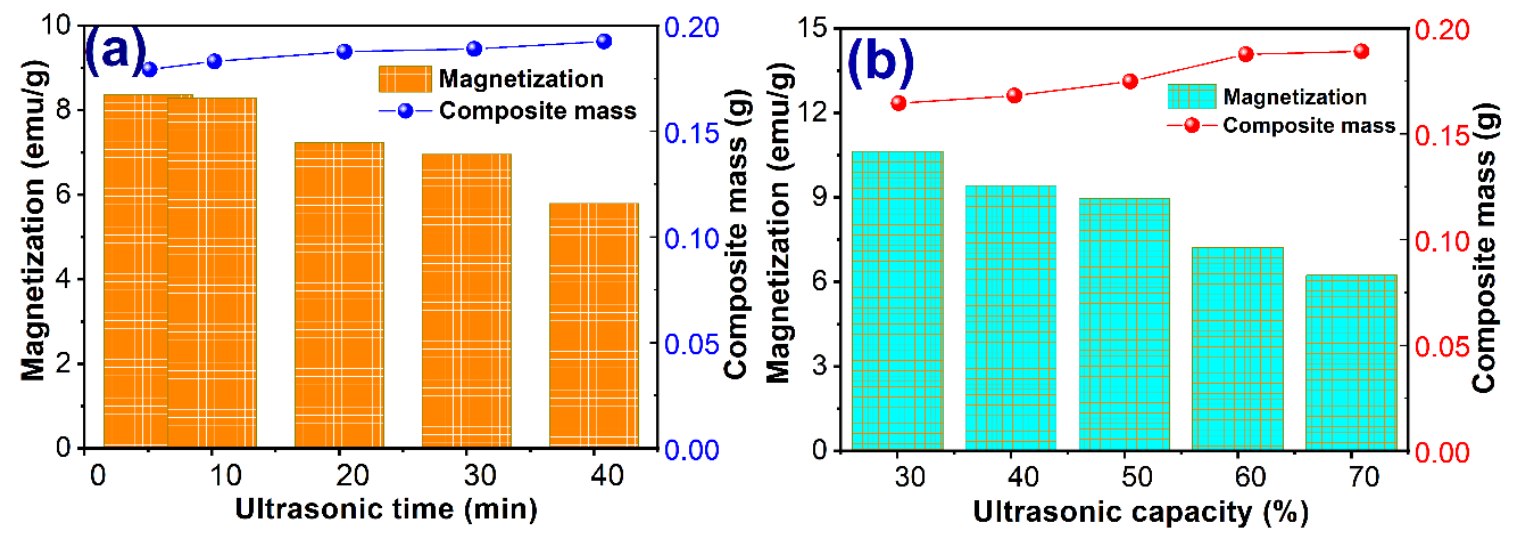

Fig. 8. The amount and magnetization of the obtained NCs at various (a) ultrasonic times; and (b) ultrasonic capacities

Similarly, Fig. 8b demonstrated the amount and magnetization of the obtained NCs at various ultrasonic capacities (30\% to 70\%). As shown in Fig. 8b, when the ultrasonic power was increased, both the energy supplied to the reaction mixture and the movement of the magnetic nanoparticles also were increased. This resulted in collisions between the magnetic nanoparticles and pectin particles, thus increasing the amount of collected NCs. However, when the ultrasonic power was increased from $60 \%$ to $70 \%$, the collected composite content slightly increased, while the magnetization remarkably decreased. This result was explained in a similar method to the aforementioned case of the ultrasound time effect; therefore, an ultrasonic capacity of $60 \%$ was deemed the most suitable for this study.

\section{Characteristics of the Nanocomposite (NCs)}

The physical-chemical properties of the NCs were analyzed via FTIR, TG-DSC, SEM, and XRD to identify the functional groups, thermal stability, surface morphology, and crystal structure changes of the magnetic nanoparticles, respectively. The analysis results of the FTIR and TG-DSC of the NCs are presented in Fig. 9.
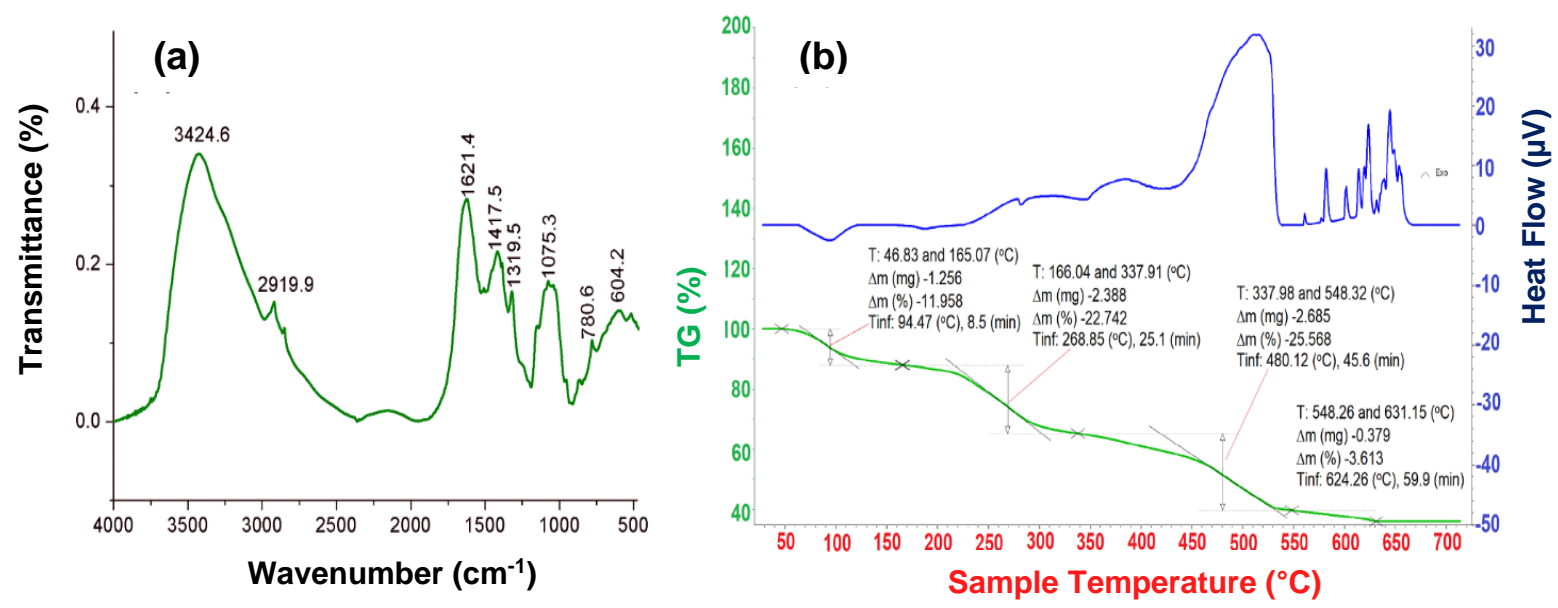

Fig. 9. Results of the (a) FTIR and (b) the TG-DSC of the NCs

The FTIR analysis results of the NCs (Fig. 9a) showed that there was a Fe-O bond valence oscillation absorption peak at $604.2 \mathrm{~cm}^{-1}$, which was a characteristic fluctuation of 
$\mathrm{CoFe}_{2} \mathrm{O}_{4}$. The strong fluctuation at $3424.6 \mathrm{~cm}^{-1}$ was the specific oscillation of the $-\mathrm{OH}$ group. The peak at $1631.0 \mathrm{~cm}^{-1}$ was further evidence of the presence of $-\mathrm{OH}$ groups. The appearance of $-\mathrm{OH}$ groups was beneficial for bonding with pectin particles. The fluctuations at 1621.4 and $1417.5 \mathrm{~cm}^{-1}$ were characteristic for the $\mathrm{C}=\mathrm{O}$ group in COO- for symmetric and asymmetric structures (Goycoolea and Cárdenas 2003; Atkinson et al. 2008). The fluctuations at 1621.4 and $1417.5 \mathrm{~cm}^{-1}$ were also considered symmetric and asymmetric metal carboxylate bonds (COO - Fe) (Iida et al. 2007; Yuan et al. 2010; Zhang et al. 2011; Namanga et al. 2013; Rampino et al. 2016). The wave separation degree value $(\Delta)$ between the absorption bands of $v_{\text {as }}(\mathrm{COO}-)$ and $v_{\mathrm{s}}(\mathrm{COO}-)$ can be used to classify the interaction between the terminal carboxylates and metal atoms. The $\Delta$ value (1621.4 $\left.1417.5=203.9 \mathrm{~cm}^{-1}\right)$ was assigned to the bidentate bridge between COO- and $\mathrm{Fe}^{2+}$ and $\mathrm{Fe}^{3+}$ (Wilson et al. 2002; Guo et al. 2010; Namanga et al. 2013).

Figure $9 \mathrm{~b}$ presented the TG-DSC analysis results of the NCs. At a temperature range of 46.8 to $165.1{ }^{\circ} \mathrm{C}$, the mass reduction of $12.0 \%$, which corresponded with the endothermic peak at $94.5{ }^{\circ} \mathrm{C}$, indicated that the $\mathrm{NCs}$ was not in free-form and formed hydrogen bonds with water. At a temperature range of 166.0 to $337.9^{\circ} \mathrm{C}$, the corresponding exothermal peak appeared at $268.8^{\circ} \mathrm{C}$, and led to a major decrease in NCs content $(22.7 \%)$. At a temperature range of 338.0 to $548.3{ }^{\circ} \mathrm{C}$, the $\mathrm{NCs}$ with strong exothermal peaks at $480.1{ }^{\circ} \mathrm{C}$ caused the NCs content to sharply decrease $(25.6 \%)$. At a temperature range of 548.3 to $631.2{ }^{\circ} \mathrm{C}$, there was a slight decrease the NCs content (3.61\%), which corresponded with the appearance of the weak exothermal peak at $624.3{ }^{\circ} \mathrm{C}$. From the analysis results, it can be seen that the remaining NC content was greater than $36.1 \%$, while the remaining pectin content was $30.4 \%$, which showed that the NCs were more heat resistant than the pectin. Published works on the synthesis of composite materials using a mixture of magnetic nanoparticles $\left(\mathrm{Fe}_{3} \mathrm{O}_{4}\right)$ based on polymer substrates also reported similar results (Wilson et al. 2002; Guo et al. 2010; Namanga et al. 2013). However, the flocculation process for the recovery of microalgae was carried out at room temperature, so the synthesized nanocomposite material did not undergo thermal degradation.

The SEMs at various magnifications and the XRDs of the synthesized NCs are shown in Fig. 2S. Figure 2Sa shows that the surface of the NCs was relatively rough with a cube spinel. However, the composite materials were dispersed into wastewater during the flocculation process; thus the surface morphology of the NCs was only slightly affected by the flocculation process.

The XRD results (Fig. 2Sb) indicated that the diffraction pattern perfectly matched the standard data (JCPDS card, No. 22-1086). In addition, the XRD data confirmed the cube spinel structure of the $\mathrm{CoFe}_{2} \mathrm{O}_{4}$ magnetic nanoparticles (Bui et al. 2011; ZieliskaJurek et al. 2012; Vadivel et al. 2015). From XRD results, it can be seen that the crystal structure of the $\mathrm{CoFe}_{2} \mathrm{O}_{4}$ magnetic nanoparticles that contained synthesized $\mathrm{NC}$ material has been insignificantly changed.

\section{The Effect of the Type of Flocculant on the Microalgae Recovery Efficiency}

The experiment to investigate the effects of various flocculants on microalgae recovery was conducted at an initial Tetraselmis microalgae concentration of $255^{*} 10^{6}$ cells $/ 50 \mathrm{~mL}$ or $5.1 * 10^{6}$ cell $/ \mathrm{mL}$ equivalent with $1.51 \mathrm{~g} / \mathrm{L}$, with $1.0 \mathrm{~g}$ of each flocculant. The microalgae recovery efficiency values using various flocculants (pectin, hydroxyl modified magnetic nanoparticles, and nanocomposites) are shown in Table 2. 
Table 2. Microalgae Recovery Efficiency Using Various Coagulants

\begin{tabular}{|c|c|}
\hline Coagulant & Microalgae Flocculation Efficiency \\
\hline Nopal pectin & 34.33 \\
\hline MMNPs & 98.12 \\
\hline Nanocomposites & 99.51 \\
\hline
\end{tabular}

Table 2 shows that the microalgae flocculation ability of the MMNPs and nanocomposites (NCs) were almost identical and far better compared to Nopal pectin. Thus, the next experiments were conducted using both MMNPs and NCs to investigate the factors affecting microalgae flocculation efficiency.

\section{The Effect of the Flocculant Dosage, Agitation Rate, and Agitation Time on the Microalgae Flocculation Process}

All experiments were performed with an initial Tetraselmis microalgae content $1.26,1.33$, and $1.29 \mathrm{~g} / \mathrm{L}$ dry weight, respectively, at a $\mathrm{pH}$ of 7 in order to investigation the effects of the dosage, agitation rate, and agitation time on the microalgae flocculation process during the rapid stirring stage. The results in Fig. 10a indicated that the microalgae recovery efficiency increased from $59.6 \%$ to $84.1 \%$ when MMNPs were used, and this efficiency increased from $57.3 \%$ to $96.3 \%$ when NCs were used in conjunction with an increase in flocculant dosage (from $0.05 \mathrm{~g}$ to $0.20 \mathrm{~g}$ ). The highest flocculation efficiency was reached at a flocculant dosage of $0.20 \mathrm{~g}$ for both types of used flocculants with a maximum coagulated material amount of $2.0 \mathrm{~g}$. When the same dosage of flocculant was used, the NCs had higher flocculation efficiency than the MNNPs. However, there was a considerable decreasing trend in flocculation efficiency when using a higher flocculant dosage for both MMNPs and NCs $(0.25 \mathrm{~g})$. This can be explained by the fact that an increase in flocculant dosage caused an increase in particle density; therefore, the collision probability between the particles increased, resulting in a breaking down of the floc in the aqueous solution.

From Fig. 10b, it can be seen that the microalgae flocculation increased when the agitation rate increased. The microalgae flocculation efficiency using MMNPs and NCs increased from $40.5 \%$ to $83.3 \%$ and $56.1 \%$ to $98.8 \%$, respectively, which corresponded to an agitation rate of $100 \mathrm{rpm}, 150 \mathrm{rpm}$, and $200 \mathrm{rpm}$. In general, the microalgae flocculation efficiency when using NCs was higher than the flocculation efficiency when using MMNPs. However, there was a slight decreasing trend in the flocculation of microalgae when the agitation rate was at $250 \mathrm{rpm}$. The aim of the agitation during the microalgae flocculation process is to make a close contact between the flocculant and microalgae, which will effectively enhance the flocculation process. However, a slow agitation rate resulted in poor contact between the microalgae and flocculant, but a fast agitation rate caused the flocs to break down as well as a decreased flocculation efficiency. The results were in accordance with previous studies on microalgae recovery using various flocculants (Liu et al. 2009; Xu et al. 2013; Chen et al. 2014).

The results showing the effect of the agitation time on the microalgae flocculation process are presented in Fig. 10c. It was revealed that the flocculation efficiency increased as the agitation time was increased and reached a maximum value at $3 \mathrm{~min}$. However, a longer agitation time ( $4 \mathrm{~min}$ ) was found to decrease the flocculation efficiency. This could be due to in the initial stage of flocculation (the fast agitation stage), favorably promoting contact between the flocculant and microalgae; the longer the contact time, the higher the

Nguyen et al. (2021). "Nopal cactus \& algae removal," BioResources 16(2), 3469-3493. 3485 
flocculation efficiency reached. However, a strong and fast agitation rate for a long period of time led to the flocs breaking down and thus the microalgae flocculation efficiency decreased.
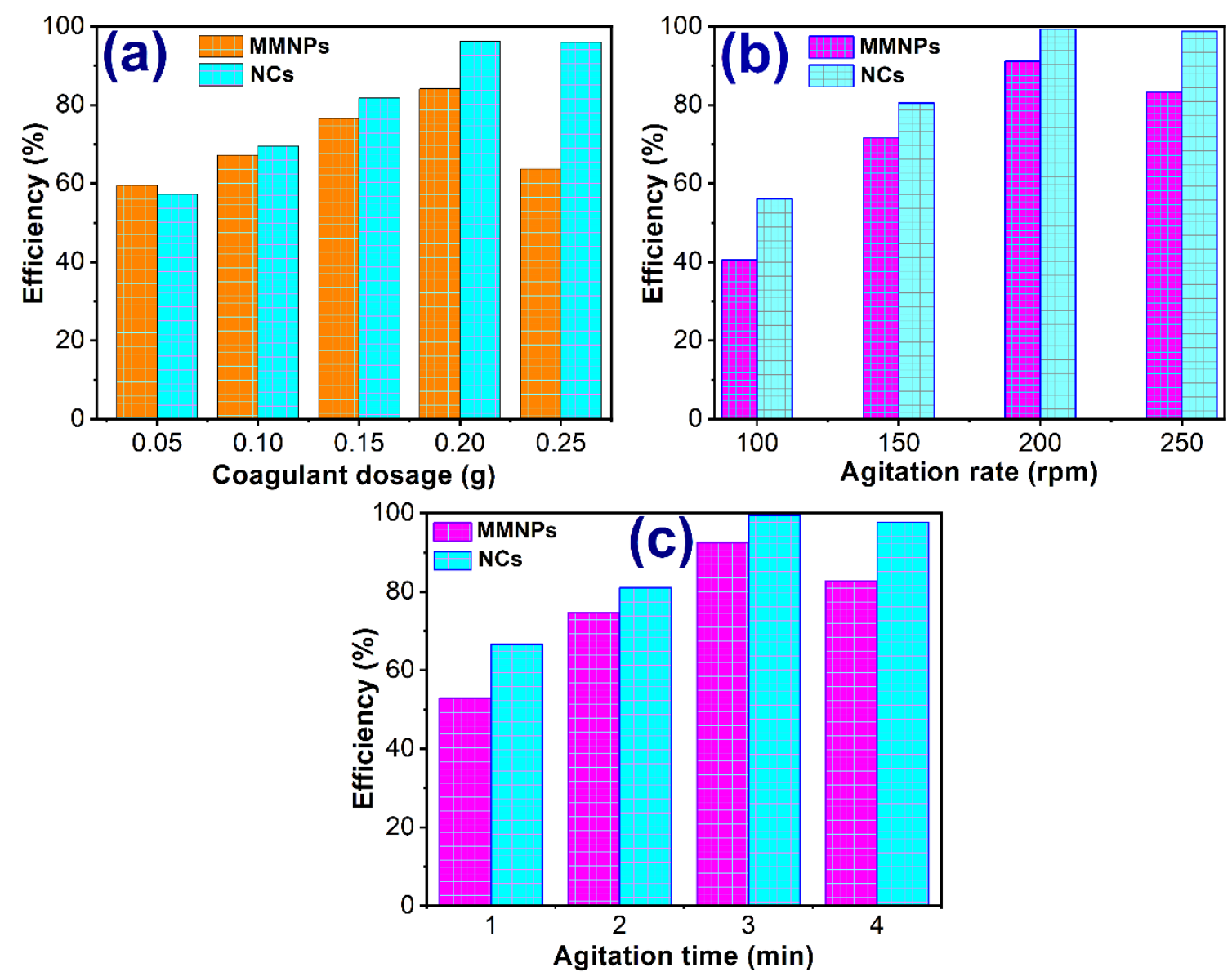

Fig. 10. The effects of the (a) flocculant dosage; (b) agitation rate; and (c) agitation time on the microalgae flocculation during the rapid stirring stage

The effect of the agitation rate on the microalgae flocculation process during the slow stirring stage was conducted with an initial microalgae content of $1.11 \mathrm{~g}$ dry weight/L. Figure 11a indicates that as the agitaion rate increased, the flocculation efficiency increased for both of the used nanoparticle materials. When the agitation rate was increased from 30 rpm to $50 \mathrm{rpm}$, the flocculation efficiency increased from $58.6 \%$ to $86.6 \%$ for MMNPs and from $74.0 \%$ to $82.6 \%$ for NCs.

There was no major difference between the flocculation efficiency of microalgae when agitation rate was further increased. During the slow stirring stage, a high agitation rate broke down the flocs, which led to a reduced ability in making bridge bonding between the biopolymer and microalgae. This caused the dispersion of microalgae back to water, and thus the flocculation efficiency decreased. Conversely, the flocculant was not uniformly dispersed in the water medium when the agitation rate was too slow, which led to poor collision and contact of the colloids, and thus the flocculation efficiency decreased. Therefore, the most suitable agitation rate in this study was $50 \mathrm{rpm}$. 

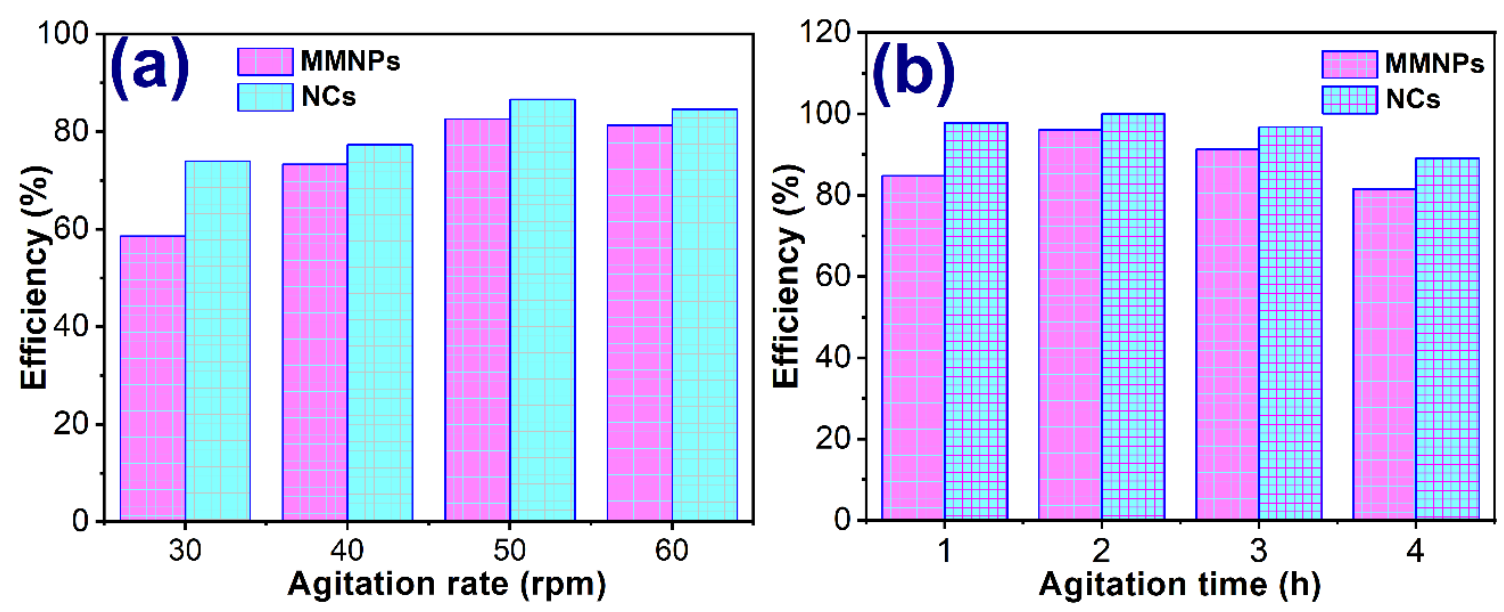

Fig. 11. The effects of the (a) agitation rate; and (b) agitation time on the microalgae flocculation process during the slow stirring stage

Figure $11 \mathrm{~b}$ shows that the flocculation efficiency was the highest when the stirring time was increased from $1 \mathrm{~min}$ to $2 \mathrm{~min}$. Nonetheless, there was a slight decrease in the flocculation efficiency when the stirring time was further increased. This could be due to the fact that slow stirring for a long time during the slow stirring stage of the flocculation process produced broken flocs, which resulted in a decrease in the bridge bonding ability between the microalgae and the biopolymer. Conversely, a short agitation time caused ununiformed dispersion of the biopolymer into the aqueous solution, thus the contact between the bioplymer and microalgae cells was poor and yielded a low microalgae recovery efficiency. The similar results also were found in previous studies by Ho et al. (2009) and Ho et al. (2010).

\section{CONCLUSIONS}

1. This study was succesful in developing a green flocculant derived from Nopal cactus in combination with magnetic nanoparticiples for the flocculation of microalgae from an aqueous solution.

2. The effects of various factors on the pectin extraction process and modification and fabrication of the flocculant were systematically investigated. In this study, a three-stage pectin extraction procedure from Nopal cactus was performed. The optimal parameters affecting the process efficiency, including the $\mathrm{pH}$ of the solution and chemical agents were achieved. The optimal $\mathrm{pH}$ values of the reduction, separation, and collection procedure during the pectin extraction were 4.0, 10.0, and 2.0, respectively. The chemical agents that yielded the highest collection efficiency of pectin were $\mathrm{HCl}$ and $\mathrm{NaOH}$ at an acid concentration of $1.0 \mathrm{~mol} / \mathrm{L}$ for the reduction and separtion processes of pectin, respectively.

3. For the fabrication of nanocomposites (NCs), the most suitable mixture ratio of MMNPs to Nopal pectin (NP) was found to be 1 to $3(\mathrm{w} / \mathrm{w})$. The obtained NCs content was maximized at $20 \mathrm{~min}$ of sonication with an ultrasonic capacity of $60 \%$. Meanwhile, the magnetization of NCs reached its highest value at $30 \mathrm{~min}$ of sonication and an ultrasonic capacity of $30 \%$. 
4. The results of the analysis of the physical-chemical characteristics showed that the green flocculant possessed high heat resistance and magnetic properties, which were consistent with the flocculation of microalgae from an aqueous solution. A comparative study of the microalgae flocculation efficiency for MMNPs and NCs at varying flocculant dosages, agitation rates, and contact times during both the rapid and slow stirring stages were conducted. The results highlighted that the microalgae flocculation process using NCs yielded higher efficiency than using MMNPs. During the rapid stirring stage, the microalgae flocculation efficiency using NCs was maximized at a flocculant dosage of 0.20 $\mathrm{g} / \mathrm{L}$, an agitation rate of $200 \mathrm{rpm}$, and an agitation time of $3 \mathrm{~min}$. During the slow stirring stage, the corresponding values were reached at $50 \mathrm{rpm}$ and a $2 \mathrm{~min}$ agitation time.

5. In summary, the green flocculant obtained from this study was low cost, highly efficient, and environmental friendly. In addition, it was especially easy to perform liquid-solid separation after the treatment process; thus it can be used as an alternative for conventional flocculants to treat wastewater and microalgae from water bodies via the coagulationflocculation process.

\section{REFERENCES CITED}

Atkinson, R. G., Schröder, R., Hallett, I. C., Cohen, D., and MacRae, E. A. (2002). "Overexpression of polygalacturonase in transgenic apple trees leads to a range of novel phenotypes involving changes in cell adhesion," Plant Physiology 129(1), $122-$ 133. DOI: 10.1104/pp.010986

Branyikova, I., Prochazkova, G., Potocar, T., Jezkova, Z., and Branyik, T. (2018). "Harvesting of microalgae by flocculation," Fermentation 4(4), 1-12. DOI: 10.3390/fermentation4040093

Bui, N. T., Dang, T. B., Le, H. V., and Phan, N. T. S. (2011). "Suzuki reaction of aryl bromides using a phosphine-free magnetic nanoparticle-supported palladium catalyst," Chinese Journal of Catalysis 32(11), 1667-1676. DOI: 10.1016/S18722067(10)60270-7

Can, K., Ozmen, M., and Ersoz, M. (2009). "Immobilization of albumin on aminosilane modified superparamagnetic magnetite nanoparticles and its characterization," Colloids and Surfaces B: Biointerfaces 71(1), 154-159. DOI: 10.1016/j.colsurfb.2009.01.021

Cárdenas, A., Goycoolea, F. M., and Rinaudo, M. (2008). "On the gelling behaviour of 'nopal' (Opuntia ficus indica) low methoxyl pectin," Carbohydrate Polymers 73(2), 212-222. DOI: 10.1016/j.carbpol.2007.11.017

Cerff, M., Morweiser, M., Dillschneider, R., Michel, A., Menzel, K., and Posten, C. (2012). "Harvesting fresh water and marine algae by magnetic separation: Screening of separation parameters and high gradient magnetic filtration," Bioresource Technology 118, 289-295. DOI: 10.1016/j.biortech.2012.05.020

Chatsungnoen, T., and Chisti, Y. (2016). "Harvesting microalgae by flocculationsedimentation," Algal Research 13, 271-283. DOI: 10.1016/j.algal.2015.12.009

Chen, G., Zhao, L., Qi, Y., and Cui, Y.-L. (2014). "Chitosan and its derivatives applied in harvesting microalgae for biodiesel production: An outlook," Journal of Nanomaterials 2014, 1-9. DOI: 10.1155/2014/217537

Gandha, K., Elkins, K., Poudyal, N., and Liu, J. P. (2015). "Synthesis and 
characterization of $\mathrm{CoFe}_{2} \mathrm{O}_{4}$ nanoparticles with high coercivity," Journal of Applied Physics 117(17), 2-6. DOI: 10.1063/1.4916544

Goycoolea, F. M., and Cárdenas, A. (2003). "Pectins from Opuntia spp.: A short review," Journal of the Professional Association for Cactus Development 5, 17-29.

Granados, M. R., Acién, F. G., Gómez, C., Fernández-Sevilla, J. M., and Grima, E. M. (2012). "Evaluation of flocculants for the recovery of freshwater microalgae," Bioresource Technology 118, 102-110. DOI: 10.1016/j.biortech.2012.05.018

Guillard, R. R. L., and Sieracki, M. S. (2005). "Counting cells in cultures with the light microscope," in: Algal Culturing Techniques, R. A. Andersen (ed.), Elsevier Academic Press, Burlington, Massachusetts, pp. 239-252.

Guo, L., Liu, G., Hong, R.-Y., and Li, H.-Z. (2010). "Preparation and characterization of chitosan poly(acrylic acid) magnetic microspheres," Marine Drugs 8(7), 2212-2222. DOI: $10.3390 / \mathrm{md} 8072212$

Ho, Y. C., Norli, I., Alkarkhi, A. F. M., and Morad, N. (2009). “Analysis and optimization of flocculation activity and turbidity reduction in kaolin suspension using pectin as a biopolymer flocculant," Water Science and Technology 60(3), 771781. DOI: $10.2166 /$ wst.2009.303

Ho, Y. C., Norli, I., Alkarkhi, A. F. M., and Morad, N. (2010). "Characterization of biopolymeric flocculant (pectin) and organic synthetic flocculant (PAM): A comparative study on treatment and optimization in kaolin suspension," Bioresource Technology 101(4), 1166-1174. DOI: 10.1016/j.biortech.2009.09.064

Iida, H., Takayanagi, K., Nakanishi, T., and Osaka, T. (2007). "Synthesis of $\mathrm{Fe}_{3} \mathrm{O}_{4}$ nanoparticles with various sizes and magnetic properties by controlled hydrolysis," Journal of Colloid and Interface Science 314(1), 274-280. DOI: 10.1016/j.jcis.2007.05.047

Joye, D. D., and Luzio, G. A. (2000). "Process for selective extraction of pectins from plant material by differential pH," Carbohydrate Polymers 43(4), 337-342. DOI: 10.1016/S0144-8617(00)00191-0

Kazemzadeh, B., Hosseinzadeh, H., and Babazadeh, M. (2013). "Synthesis of a novel pectin-based superabsorbent hydrogel with salt and $\mathrm{pH}$-responsiveness properties," Biomedical and Pharmacology Journal 6(1), 41-48.

Kim, Y. I., Kim, D., and Lee, C. S. (2003). "Synthesis and characterization of $\mathrm{CoFe}_{2} \mathrm{O}_{4}$ magnetic nanoparticles prepared by temperature-controlled coprecipitation method," Physica B: Condensed Matter 337(1-4), 42-51. DOI:10.1016/S0921-4526(03)00322-3

Lim, J. K., Chieh, D. C. J., Jalak, S. A., Toh, P. Y., Yasin, N. H. M., Ng, B. W., and Ahmad, A. L. (2012). "Rapid magnetophoretic separation of microalgae," Small 8(11), 1683-1692. DOI: 10.1002/smll.201102400

Liu, D., Li, F., and Zhang, B. (2009). "Removal of algal blooms in freshwater using magnetic polymer," Water Science and Technology 59(6), 1085-1091. DOI:

10.2166/wst.2009.046

Matter, I. A., Bui, V. K. H., Jung, M., Seo, J. Y., Kim, Y.-E., Lee, Y.-C., and Oh, Y.-K. (2019). "Flocculation harvesting techniques for microalgae: A review," Applied Sciences 9(15), 1-27. DOI: 10.3390/app9153069

McNeary, W. W., and Erickson, L. E. (2013). "Sustainable management of algae in eutrophic ecosystems," Journal of Environmental Protection 4(11), 9-19. DOI: 10.4236/jep.2013.411a002

Milledge, J. J., and Heaven, S. (2013). "A review of the harvesting of micro-algae for biofuel production," Reviews in Environmental Science and Bio/Technology 12(2), 
165-178. DOI: 10.1007/s11157-012-9301-z

Muazu, J., Alpha, A., and Mohammed, G. T. (2014). "Isolation and release retardant properties of a plant gum obtained from ayoyo," Caribbean Journal of Science and Technology 2, 301-313.

Namanga, J., Foba, J., Ndinteh, D. T., Yufanyi, D. M., and Krause, R. W. M. (2013). "Synthesis and magnetic properties of a superparamagnetic nanocomposite 'pectinmagnetite nanocomposite'," Journal of Nanomaterials 2013, 1-9. DOI: $10.1155 / 2013 / 137275$

Phan, N. T. S., and Jones, C. W. (2006). "Highly accessible catalytic sites on recyclable organosilane-functionalized magnetic nanoparticles: An alternative to functionalized porous silica catalysts," Journal of Molecular Catalysis A: Chemical 253(1-2), 123 131. DOI: 10.1016/j.molcata.2006.03.019

Ramazani, A., Sadri, F., Massoudi, A., Khoobi, M., Joo, S. W., Dolatyari, L., and Dayyani, N. (2015). "Magnetic $\mathrm{ZnFe}_{2} \mathrm{O}_{4}$ nanoparticles as an efficient catalyst for the oxidation of alcohols to carbonyl compounds in the presence of oxone as an oxidant," Iranian Journal of Catalysis 5(3), 285-291.

Rampino, A., Borgogna, M., Bellich, B., Blasi, P., Virgilio, F., and Cesàro, A. (2016). "Chitosan-pectin hybrid nanoparticles prepared by coating and blending techniques," European Journal of Pharmaceutical Sciences 84, 37-45. DOI: 10.1016/j.ejps.2016.01.004

Renault, F., Sancey, B., Badot, P.-M., and Crini, G. (2009). "Chitosan for coagulation/ flocculation processes - An eco-friendly approach,” European Polymer Journal 45(5), 1337-1348. DOI: 10.1016/j.eurpolymj.2008.12.027

Srivastava, P., and Malviya, R. (2011). "Sources of pectin, extraction and its applications in pharmaceutical industry - An overview," Indian Journal of Natural Products and Resources, 2(1), 10-18.

Stanier, R. Y., Kunisawa, R., Mandel, M., and Cohen-Bazire, G. (1971). "Purification and properties of unicellular blue-green algae (order Chroococcales)," Bacteriological Reviews 35(2), 171-205.

Teh, C. Y., Budiman, P. M., Shak, K. P. Y., and Wu, T. Y. (2016). "Recent advancement of coagulation-flocculation and its application in wastewater treatment," Industrial \& Engineering Chemistry Research 55(16), 4363-4389. DOI: 10.1021/acs.iecr.5b04703

Tien, N. A., and Tuyet, H. T. (2015). "Synthesis, structure and magnetism of $\mathrm{CoFe}_{2} \mathrm{O}_{4}$ nanomaterials by co-precipitation method," Vietnam Journal of Chemistry 53(3), 441444. DOI: 10.15625/0866-7144.2015-00159

Vadivel, M., Babu, R. R., Arivanandhan, M., Ramamurthi, K., and Hayakawa, Y. (2015). "Role of SDS surfactant concentrations on the structural, morphological, dielectric and magnetic properties of $\mathrm{CoFe}_{2} \mathrm{O}_{4}$ nanoparticles," RSC Advances 5(34), 2706027068. DOI: 10.1039/C5RA01162K

Vandamme, D., Foubert, I., and Muylaert, K. (2013). "Flocculation as a low-cost method for harvesting microalgae for bulk biomass production," Trends in Biotechnology 31(4), 233-239. DOI: 10.1016/j.tibtech.2012.12.005

Wilson, K. S., Harris, L. A., Goff, J. D., Riffle, J. S., and Dailey, J. P. (2002). “A generalized method for magnetite nanoparticle steric stabilization utilizing block copolymers containing carboxylic acids," European Cells and Materials 3(2), 206209.

Xu, L., Guo, C., Wang, F., Zheng, S., and Liu, C.-Z. (2011). “A simple and rapid harvesting method for microalgae by in situ magnetic separation," Bioresource 
Technology 102(21), 10047-10051. DOI: 10.1016/j.biortech.2011.08.021

Xu, Y., Purton, S., and Baganz, F. (2013). "Chitosan flocculation to aid the harvesting of the microalga Chlorella sorokiniana," Bioresource Technology 129, 296-301. DOI: 10.1016/j.biortech.2012.11.068

Yang, K., Li, Y.-J., and Chen, Y.-C. (2013). "Removal of oil and Cr(VI) from wastewater using modified pectin flocculants," American Society of Civil Engineers 140, 04013004-1-04013004-10. DOI: 10.1061/(ASCE)EE .1943-7870.0000793

Yazid, N.-A, and Joon, Y. C. (2019). "Co-precipitation synthesis of magnetic nanoparticles for efficient removal of heavy metal from synthetic wastewater," AIP Conference Proceedings 2124, 020019 (2019). DOI:10.1063/1.5117079

Yuan, D., Zhang, Q., and Dou, J. (2010). "Supported nanosized palladium on superparamagnetic composite microspheres as an efficient catalyst for Heck reaction," Catalysis Communications 11(7), 606-610. DOI: 10.1016/j.catcom.2010.01.005

Zhang, X., Li, P., Ji, Y., Zhang, L., and Wang, L. (2011). “An efficient and recyclable magnetic-nanoparticle-supported palladium catalyst for the Suzuki coupling reactions of organoboronic acids with alkynyl bromides," Synthesis (18), 2975-2983. DOI: $10.1055 / \mathrm{s}-0030-1260138$

Zielińska-Jurek, A., Reszczyńska, J., Grabowska, E., and Zalesk, A. (2012). "Nanoparticles preparation using microemulsion systems," in: Microemulsions - An Introduction to Properties and Applications, R. Najjar (ed.), IntechOpen, London, United Kindom.

Article submitted: January 2, 2021; Peer review completed: February 21, 2021; Revised version received and accepted: March 10, 2021; Published: March 23, 2021.

DOI: 10.15376/biores.16.2.3469-3493 


\section{SUPPLEMENTAL}
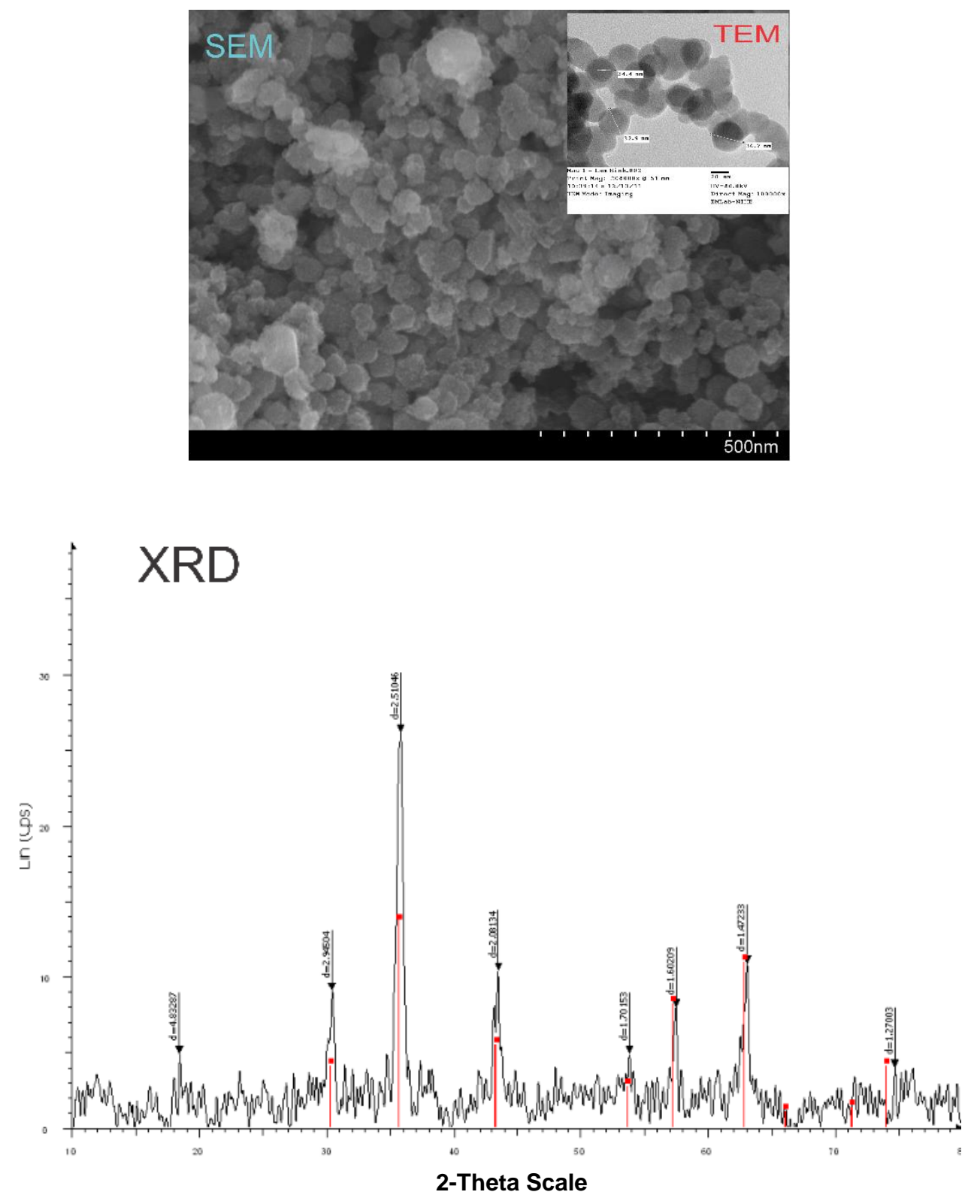

Fig. S1. (a) SEM and TEM images and (b) XRD of modified magnetic nanoparticles (MMNPS) 

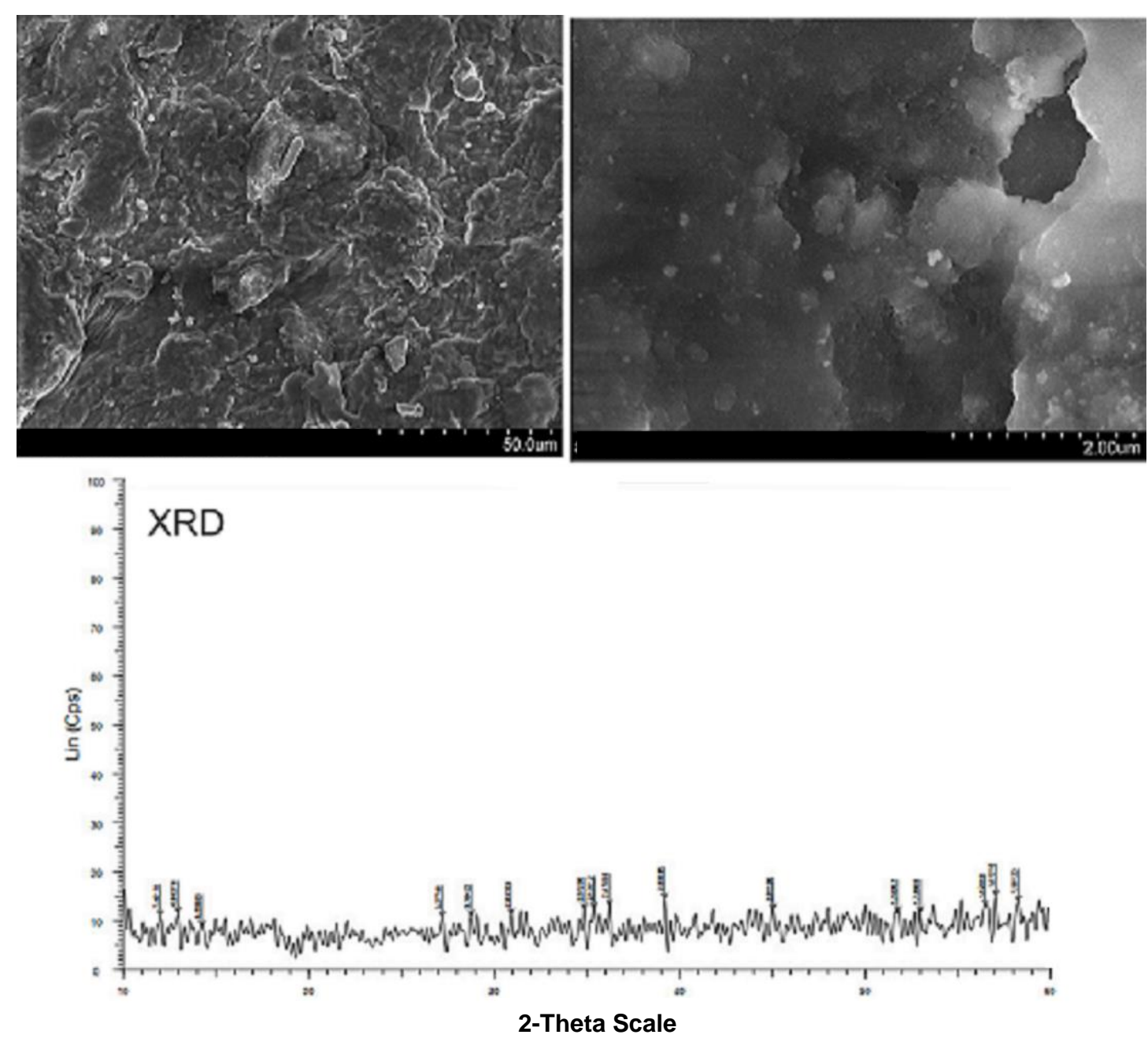

Fig. S2. (a) The SEM and (b) XRD of NCs 